\title{
Nonlinear Photonic Signal Processing Subsystems and Applications
}

\author{
Chi-Wai Chow ${ }^{1}$ and Yang Liu ${ }^{2}$ \\ ${ }^{1}$ Department of Photonics, National Chiao Tung University, \\ ${ }^{2}$ Material and Packaging Technologies Group, Hong Kong Applied Science and Technology \\ Research Institute Company limited, \\ 1Taiwan \\ ${ }^{2}$ Hong Kong
}

\section{Introduction}

Over the last decade, the world has seen a great transformation in telecommunication, storage, multimedia, and entertainment. This is mainly due to the advances in computers and Internet, which were made possible by the various advances in lasers and high-capacity optical communication technologies. Without the invention of lasers and fiber optic communication systems, current global telecommunication infrastructure and Internet would have been impossible. The deployment of the optical communication systems started at the 1970s. The bit rate of the early stage fiber optic communication systems in 1980 was $\sim 100 \mathrm{Mb} / \mathrm{s}$, increasing to $1.25 \mathrm{~Gb} / \mathrm{s}, 2.5 \mathrm{~Gb} / \mathrm{s}$ and $10 \mathrm{~Gb} / \mathrm{s}$ over the past three decades. By using the wavelength division multiplexing (WDM) technology developed in the 1990s, systems supporting > 100 wavelength channels increase the total capacities up to $1 \mathrm{~Tb} / \mathrm{s}$ (Kehayas, 2009). Recently, commercial deployments of WDM and dense WDM (DWDM) systems with $40 \mathrm{~Gb} / \mathrm{s}$ per wavelength channel have started.

This increase in traffic capacity will generate problems. One of them is the huge power consumption required by the network equipments. The DWDM requires optical-toelectrical $(\mathrm{O} / \mathrm{E})$ and electrical-to-optical (E/O) signal conversions with the same number as that of the wavelength, resulting in an increase in power consumption. Besides, the high speed electrical signal processing of packet routing and switching at the router consumes huge amounts of power. Apart from the huge power consumption, recent advances in optical signal generations, modulation formats, detections and post-detection signal processing have made the single channel bit rate $>100 \mathrm{~Gb} / \mathrm{s}$. This creates the so-called "electronic bottle-neck" between the data transmission rate of optical systems and the limited processing speed of electronic systems. The mismatch between the processing speeds of electronics and photonics stimulates many researches and developments of the nonlinear photonic signal processing technologies in an attempt to remove the electronic bottle-neck. Ultra-fast optical switching using a nonlinear fiber-loop mirror (NOLM) has been demonstrated as early as 1988. And the research activities of the nonlinear photonic signal processing have been continued with the aims to reduce the switching energy and increase the processing speed. Although the processing speed of electronic circuit has increased a lot

Source: Advances in Lasers and Electro Optics, Book edited by: Nelson Costa and Adolfo Cartaxo, ISBN 978-953-307-088-9, pp. 838, April 2010, INTECH, Croatia, downloaded from SCIYO.COM 
in the past decades, nonlinear photonic signal processing still plays an important role (Willner, 2008). Nonlinear photonic signal processing techniques, such as alloptical demultiplexing, all-optical sampling, all-optical signal regeneration and all-optical wavelength conversion are more effective (particularly at high speed) and require less power than their electronic counterparts. Owing to the envision of high capacity optical time division multiplexing (OTDM)/WDM networks with transparent connectivity in the future, recently an European Union funded project TRIUMPH (http://www.ihq.unikarlsruhe. $\mathrm{de} /$ research/projects/TRIUMPH/) has been established. This project is to develop systems and switch node with optical grooming and multi-wavelength regeneration functionalities for transparent metro and core networks interconnection. Internet has provided a huge impact on our daily life. We have gained the benefit of networks; however, we are also facing the problem of increased power consumption and limited processing speeds of the electronics. We are required to establish new technologies, such as nonlinear photonic signal processing, that enable transmission of huge capacity data with minimum power consumption.

This chapter is organized as following: In Section 2, we will discuss various functions of nonlinear photonic signal processing that may be needed inside the switch node in the future Internet, including wavelength conversion, WDM-to-OTDM and OTDM-to-WDM conversions, all-optical de-multiplexing, and all-optical regeneration. In Section 3, we will discuss the nonlinear photonic signal processing using silicon-on-insulator (SOI). The potential for low cost mass production using complementary metal oxide semiconductor (CMOS) fabrication techniques makes SOI an attractive platform for the monolithic integration of optical waveguides and photonic signal processing functional devices. Finally, a conclusion will be given in Section 4 .

\section{Functions of photonic signal processing}

\subsection{Wavelength conversion}

Wavelength conversion is one of the most important functions of photonic signal processing in future optical networks. All-optical wavelength routing is a technique which allows optical signals to be routed according to their wavelength, without the need of $\mathrm{O} / \mathrm{E}$ and E/O conversions. The realization of all-optical networks (AON) can potentially introduce significant cost savings for high speed data networks (Ramaswami \& Sivarajan, 1994, Raghavan \& Upfal, 1994, Birman \& Kershenbaum, 1995). In 2000, field trials of all-optical networks in North America (Froberg et al., 2000) and Europe (Berthelon et al., 2000) have been carried out. All-optical wavelength converters can allow data at one wavelength to be transferred to another wavelength, in order to resolve collisions which would block the routing of a channel which has already been occupied by a wavelength. Besides, wavelength conversion is also important in the trans-multiplexing between the WDM-to-OTDM and OTDM-to-WDM systems (Willner, 2008). In this sub-section, we will discuss several wavelength conversion schemes based on semiconductors and fibers.

Here, we first start with the wavelength conversion scheme using semiconductor laser diode, such as Fabry-Perot laser diode (FP-LD). FP-LD is the simplest and low-cost laser that can be used as the nonlinear medium for all-optical wavelength conversion. Dualwavelength injection locking (DWIL) technique can be used for this purpose. Injection locking is a way of synchronizing one (or several) free-running oscillator(s) to a stabilized master oscillator. The technique was described in the classical papers of (van der Pol, 1927) 
and (Adler, 1946) for the case of electrical oscillators. Injection locking of microwave oscillators was reported by (Kurokawa, 1973) and injection locking of gas lasers was demonstrated by He-Ne laser (Stover \& Steier, 1966) and $\mathrm{CO}_{2}$ laser (Buczek \& Frejberg, 1972). The injection locking technique has been widely used to improve the static and dynamic performances of semiconductor lasers (Lang, 1982, Mogensen et al., 1985, Murakami et al., 2003). The waveform of the laser output response to a modulated current can be greatly improved with light injection because the transient relaxation oscillation can be severely damped (Lang \& Kobayashi, 1977). Single mode operation can be achieved (Kobayashi, 1980), a reduction of the spectral linewidth (Mogensen, 1985) can also be observed. A reduction of frequency chirping of an injection locked laser is theoretically analyzed (Piazzolla et al., 1986) and demonstrated (Lin et al., 1985), and the mode partition noise can be suppressed (Iwashita \& Nakagawa, 1982). The dispersion penalty for a signal generated by a current modulated laser can be greatly reduced by injection locking (Cartledge, 1990) and the crosstalk tolerance is also improved (Caspar et al., 1996). Moreover, the modulation bandwidth of the injection locked laser is enhanced (Chen, et al., 2000, Simpson \& Liu, 1997, Simpson \& Liu, 1996, Simpson \& Liu, 1995, Liao et al., 2009). Although the injection locking of semiconductor laser has been studied for two decades, new aspects and applications have only become apparent with recent advances in fiber optic technology. Recently, injection locked lasers have been used for different kinds of nonlinear photonic signal processing, including signal regeneration (Weich et al., 1994, Kakagawa et al., 2001, Inoue \& Oda, 1995, Yamashita \& Suzuki, 2004, Kuramoto \& Yamashita, 2003, Chan et al, 2002), optical repolarization (Chung et al., 2002, Chan et al., 2002), optical packet demultiplexing (Chan et al., 2003), modulation format conversion (Chow et al., 2003, Chow et al., 2003, Chow et al., 2002, Chang et al., 2004, Chow et al., 2004, Yeh et al., 2009). Injection locking also shows promising applications in optical packet switched networks (Chow et al., 2004), Cable-TV networks (Lu et al., 2006), passive optical networks (PONs) (Lu et al., 2006, Wang et al., 2009) and radioover- fiber (ROF) networks (Lu et al., 2008).

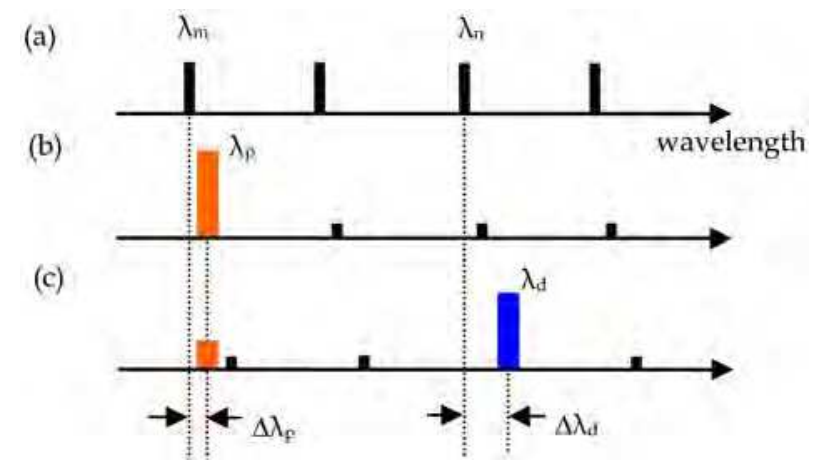

Fig. 1. Schematic of DWIL of FP-LD for all-optical wavelength conversion. (a) Longitudinal mode spectrum of the free-run FP laser, (b) spectrum under injection of only the probe signal, and (c) spectrum under injection of both probe and data signals (Horer \& Patzak, 1997).

In the scheme of DWIL (Horer \& Patzak, 1997), the slave laser was a FP-LD. The probe wavelength was a continuous-wave (CW) signal injected to an FP-LD longitudinal mode; and the pump wavelength was a modulated signal injected to another longitudinal mode. 
The output signal at the wavelength of the CW light was switched by the modulated signal, and thereby the information can be transferred from one wavelength to the other. Fig. 1 shows the schematic of DWIL using a single, direct current (dc) biased FP-LD. First, the CW probe light was injection locked one of the longitudinal modes of the FP-LD (Fig. 1(a-b)). Strong amplification took place if the wavelength of the probe light $\left(\lambda_{p}\right)$ was tuned to one of the laser modes, e.g., the $\lambda_{\mathrm{m}}$ mode. Then the mode comb was slightly red-shifted compared to its position when no light was injected and other laser modes were strongly suppressed. The data-bearing pump signal with wavelength $\lambda_{d}$ was adjusted within the locking range of another FP-LD longitudinal mode. Fig. 1 (c) shows the situation when the pump $\left(\lambda_{d}\right)$ was switched "ON". That laser mode was then resonantly amplified. This process further decreased the carrier density by stimulated emission, and further increased the refractive index in the active area of the FP-LD. The increase in refractive index led to the decrease in the FP cavity resonance frequency. The FP mode comb and simultaneously the transmission curve for the probe signal were further red-shifted. Now the probe frequency was outside the high transmission range resulting in low probe output power. Hence, the probe light can be switched "ON" and "OFF" by the data signal, and a logically inverted wavelength conversion can be achieved. The modes $\lambda_{m}$ and $\lambda_{n}$ used for conversion can be freely chosen within the gain spectrum of the FP-LD. Non-inverting operation can also be achieved. For this purpose, in the absence of data light, the probe light was adjusted with a small red-shift relative to its transmission maximum. Then, an incoming data pump signal shifted the mode toward the maximum. The amplification of the probe light increased simultaneously with the power of the data signal so that the logically non-inverting wavelength conversion was achieved.

Due to the red-shift of the laser longitudinal modes, the injection locking rang was asymmetric (Horer \& Patzak, 1997). During light injection, the laser output of a slave laser increased, and the carrier density in the active area of the laser diode decreased correspondingly. Decrease in the carrier density will increase the refractive index of the active area, resulting in the lowering of the cavity resonance frequency or red-shift of the longitudinal modes of the slave laser. When the injected signal wavelength was detuned towards the shorter wavelength side from the cavity resonance wavelength, the laser output decreased. The carrier density increasing and the refractive index decreasing caused the down-shift of the resonance wavelength, resulting in a partial compensation of the wavelength detuning. The FP-LD was still locked when the injected light wavelength was detuned towards the shorter wavelength side of a mode. On the other hand, as the injected wavelength was detuned towards the longer wavelength side, it first enhanced the laser output power due to the further depletion of carrier and further red-shift of the laser mode. Subsequent, when the injected light was outside the locking range, the downshift of the resonance wavelength of the FP-LD happened, resulting in a rapid decrease of locked output and the slave laser became unlocked.

DWIL is potentially capable of high speed all-optical switching. The speed is related to the relaxation oscillation frequency. We can increase the relaxation frequency by increasing the biased current; however for high bias current, the dynamically stable locking range is very small. This drawback can be overcome by using high external injected optical power. Hence, by using appropriate injection of optical pump, probe signal and bias current, the speed of all-optical wavelength conversion can be increased. Since injection locking is polarization sensitive, configuration using TWINS-FP (Two Wavelength Injection locked slave Fabry- 
Perot) (Chow et al., 2003) has been proposed to solve the polarization sensitivity issue of the DWIL.

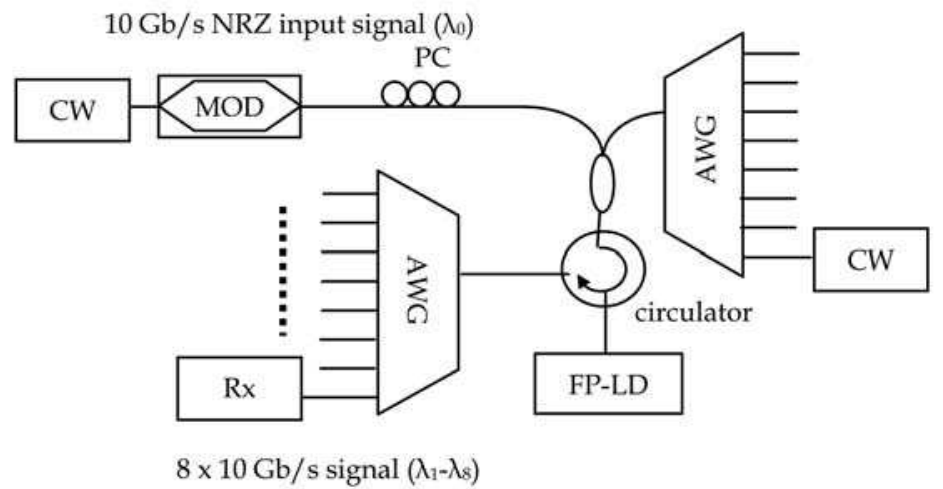

Fig. 2. Experimental setup of all-optical multicasting using a FP-LD. MOD: modulator, PC: polarization controller, AWG: arrayed waveguide grating, Rx: receiver (Chow et al., 2004).

Fig. 2 shows the experimental setup of the $8 \times 10 \mathrm{~Gb} / \mathrm{s}$ all-optical multicasting wavelength conversion using a FP-LD. The pump signal $\left(\lambda_{0}: 1547.38 \mathrm{~nm}\right)$ was encoded with $2^{31}-1$ pseudo random binary sequence $10 \mathrm{~Gb} / \mathrm{s}$ non-return-to-zero (NRZ) data. Eight $\mathrm{CW}$ probe signals (from $\lambda_{1}: 1549.03 \mathrm{~nm}$ to $\lambda_{8}: 1560.38 \mathrm{~nm}, 200 \mathrm{GHz}$ spacing) were wavelength-multiplexed by an arrayed waveguide grating (AWG). They were launched into the FP-LD, which was dc biased at $17 \mathrm{~mA}\left(2 I_{\text {th }}\right)$ and had a central wavelength of $1545.7 \mathrm{~nm}$ with the longitudinal mode spacing of about $1.6 \mathrm{~nm}$. Fig. 3 shows the optical spectrum of the multicasting wavelength conversion obtained at the output port. The side-mode suppression ratio (SMSR) of the converted signals was $\sim 30 \mathrm{~dB}$. Bit-error rate (BER) performance of the wavelength converter was performed for the $8 \times 10 \mathrm{~Gb} / \mathrm{s}$ as shown in Fig. 4. The average power penalty was about $2.5 \mathrm{~dB}$ at BER of $10^{-9}$, with channel-to-channel variation by about \pm $0.4 \mathrm{~dB}$. The eye diagrams of the multicast channel are shown in the insets of Fig. 4 . A larger number of output channels may be possible; and the maximum number of wavelength channels is determined by the gain spectrum of the FP-LD.

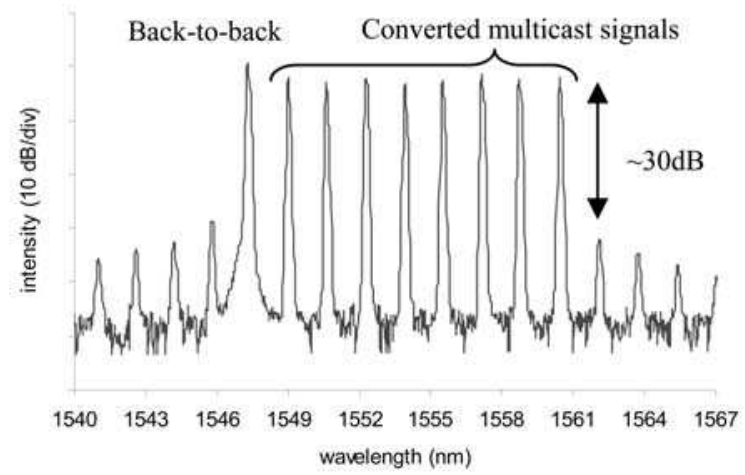

Fig. 3. Optical spectrum of the all-optical multicasting wavelength conversion using a FPLD (Chow et al., 2004). 


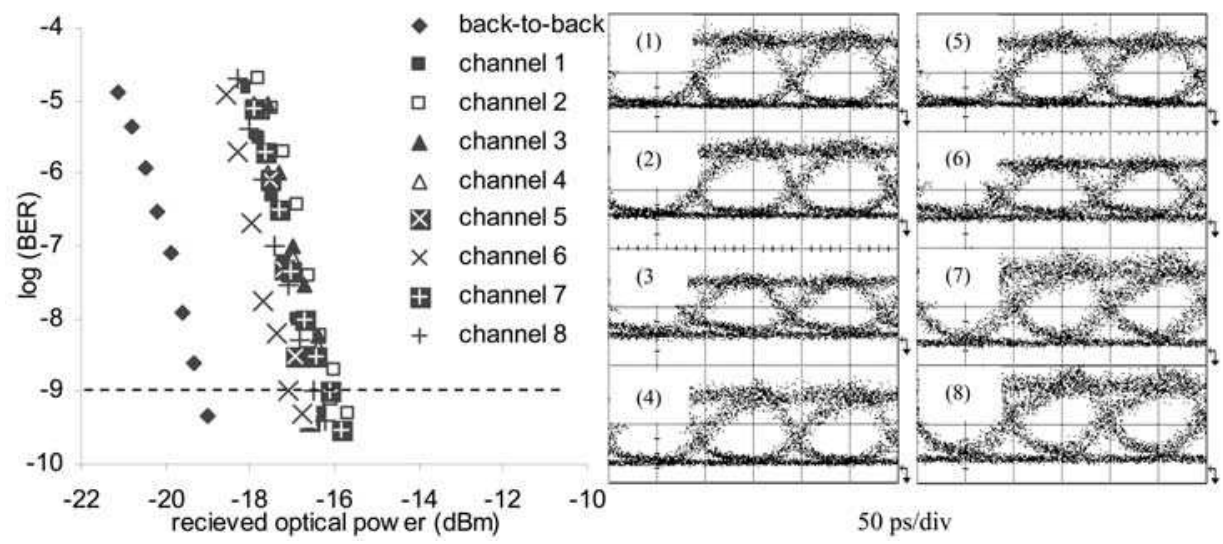

Fig. 4. Plot of $10 \mathrm{~Gb} / \mathrm{s}$ BER measurements for the back-to-back and each wavelength converted channel (channel 1-channel 8 represents $\lambda_{1}-\lambda_{8}$ respectively) (Chow et al., 2004)

Besides using FP-LD, semiconductor optical amplifier (SOA) is another essential semiconductor device for nonlinear photonic signal processing (Yoo, 1996), due to its high gain, compact size and possibilities for integration. Before studying the wavelength conversion characteristics of a SOA, we first study the SOA carrier dynamics. When an optical pulse is injected into a SOA, the majority of the electrons in the excited state are depleted due to stimulated emission. The reduction in the density of excited electrons has two consequences. First, the SOA gain is reduced, and consequently the refractive index changes as described by Kramers-Kronig relations. This causes a change in wavelength of the output pulse as a function of time (frequency chirp). The gain recovery processes following depletion by an injected optical pulse are described in this sub-section.

(a)

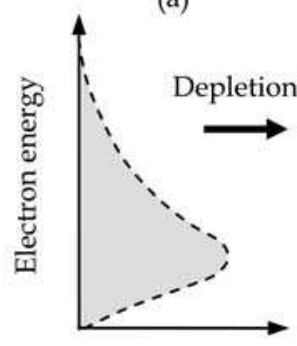

(b)

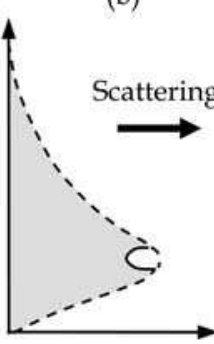

(c)

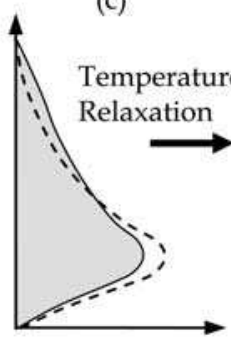

Electron density (d)

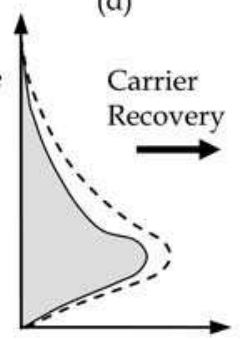

(e)

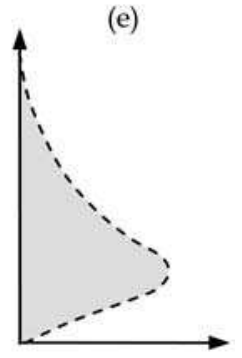

Fig. 5. Gain recovery of an SOA with the electron density versus electron energy.

Fig. 5 shows the gain recovery process of a SOA. When an optical beam is injected into a SOA, electrons in the excited states are depleted, leading to a reduction in gain. Spectral hole burning $(\mathrm{SHB})$ is a localised reduction in gain at the lasing wavelength (Gomatam \& DeFonzo, 1990) as shown in Fig. 5(b). The magnitude of gain compression generated by this effect depends on the intraband relaxation times of the carriers. There is a subsequent redistribution of carrier energies due to carrier-carrier scattering as shown in Fig. 5(c), having time scales of $<100 \mathrm{fs}$. For wavelength conversion using a SOA, the probe 
wavelength will not be affected by $\mathrm{SHB}$ as the pump signal is located at a different wavelength.

When a pump pulse is transmitted through a SOA, it reduces the carrier population but "heats" the plasma (by removing "cool" carriers), thus the gain reduces. This process is called carrier heating $(\mathrm{CH})$, which is a transient heating of electron and hole temperatures (Willatzen, 1991). Thus carriers are excited into the high momentum states. The carrier temperatures will then relax towards the lattice temperature by electron-phonon scattering on the time scales of 1-2 ps as shown in Fig. 5(c-d). The main mechanism of $\mathrm{CH}$ within the lattice structure is stimulated emission; however there are other contributions such as freecarrier absorption (FCA) and two-photon absorption (TPA). FCA is an effect where a free carrier (arising from lattice vibrations) can absorb a photon and move to a higher energy level within the band, thus increasing the temperature of the lattice (Stix et al., 1986). TPA is a process where two photons are absorbed in the generation of a single electron-hole carrier pair. It becomes dominant when the input power of the signal is high (Mork \& Mark, 1994).

Finally, interband carrier recovery takes place. It is the carriers depleted from the conduction band replenished by the applied bias current, as shown in Fig. 5(d-e). It has a time scales of tens to hundreds of ps. The interband carrier recovery time is dependent on the SOA length, the bias current and the injected optical power (Manning et al., 1994, Girardin et al., 1998).

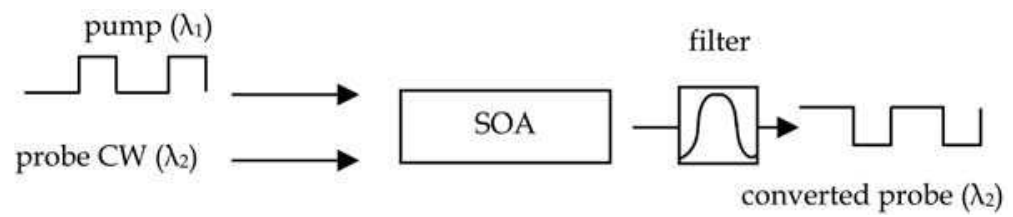

Fig. 6. Cross gain modulation (XGM) in a SOA.

After studying the carrier dynamics of a SOA, we discuss the simplest wavelength conversion using a SOA: the cross gain modulation (XGM). XGM requires a power data signal (pump) and a CW signal (probe), as shown in Fig. 6. The pump modulates the gain of the SOA; and the probe is then modulated by the gain variation of the SOA. The optical filter used will be positioned at the centre of the probe wavelength in the XGM. XGM is simple and polarisation insensitive; but the converted signal is logic inverted, having a relatively high frequency chirp, and limited extinction ratio. The speed of XGM is limited by the interband gain recovery time of SOA. The extinction ratio of the converted signal depends on the variation of the differential gain (Durhuus et al., 1996). When the SOA gain is saturated, the gain peak of the amplifier shifts to longer wavelengths, resulting in a higher slope on the shorter wavelength side of the gain peak. Hence, the probe channels at the shorter wavelengths will experience larger gain variations. As a result, down-conversion (translation from longer wavelength to shorter wavelength) can produce higher output extinction ratio in the converted signal. The extinction ratio can also be improved by increasing the input pump signal power, since this will induce a larger gain modulation of the CW probe signal.

Due to the speed limitation of XGM, modifications of the setup in Fig. 6 can be made to achieve cross phase modulation (XPM) in a SOA. As described in previous paragraph, the refractive index of a SOA is dependent on the gain, and this will cause a phase shift of the 
probe signal first to the longer wavelength side (red-shift) and then to the shorter wavelength side (blue-shift). Fig. 7 shows the probe signal has a positive phase shift corresponding to the generation of red-chirped components owing to the SOA gain depletion. Then, the SOA gain recovers resulting in a negative phase shift and the generation of blue-chirped components. Using offset filtering of wavelength converted signal in the SOA can greatly enhance the operation speed (Ellis et al., 1998). Recently, improved performance has been demonstrated up to $320 \mathrm{~Gb} / \mathrm{s}$ (Liu et al., 2006, Liu et al., 2007, Tangdiongga et al., 2006). The disadvantage of this scheme is that large portion of the optical spectrum is lost due to the offset filtering. Similar effect can also be achieved by using an asymmetric Mach-Zehnder interferometer (MZI), which is commonly referred to as a delayed-interference signal converter (DISC) (Ueno et al., 1998, Leuthold et al., 2001). It has been demonstrated that a wavelength converter based on a delayed-interferometric configuration can achieve $168 \mathrm{~Gb} / \mathrm{s}$ (Nakamura et al., 2001). A theoretical analysis for this concept of the delayed-interferometric configuration has been given in (Leuthold et al., 2004). The delayed-interferometer acts as an optical filter, and (Ueno et al., 2002, Nielsen \& Mørk, 2004, Nielsen et al., 2006) show theoretically how the optical filtering can increase the modulation bandwidth of SOA-based switches. The speed of the wavelength conversion can also be enhanced by using two cascaded SOAs, called 'Turbo-Switch' (Manning et al., 2006). Wavelength conversion can also be achieved by arranging two or more SOAs in the MZI configuration (Ratovelomanana et al., 1995, Durhuus et al., 1994, Idler et al., 1995), as shown in Fig. 8. In this scheme, the CW input is split to each arm of the MZI by a coupler. The databearing signal induces different phase shift in the input $\mathrm{CW}$ signal via carrier density induced refractive index changes. The output coupler then recombines the split CW signals, where they can interfere constructively or destructively. Commercial wavelength converter based on this structure has been available, such as from Alcatel (Idler et al., 1996).

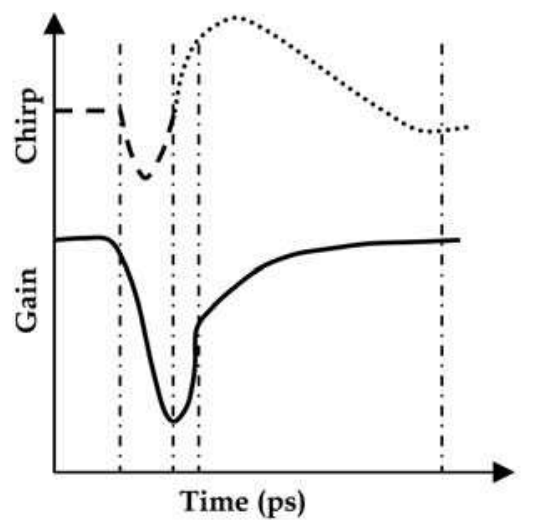

Fig. 7. The change in gain and chirp of the probe signal in a SOA when injected by a short picosecond pump pulse (Liu et al., 2006).

The mechanism of cancelling out the slow relaxation of the carrier density change can be implemented in other configurations. Using one SOA and the interference of orthogonally polarized probe light beams, called an ultrafast nonlinear interferometer (UNI) (Patel et al., 1996). Other nonlinear photonic signal processing applications using an SOA in a NOLM; also known as a semiconductor laser amplifier in a loop mirror (SLALOM) (Eiselt et al., 
1995) and terahertz optical asymmetric demultiplexer (TOAD) (Sokoloff et al., 1993) have also been reported.

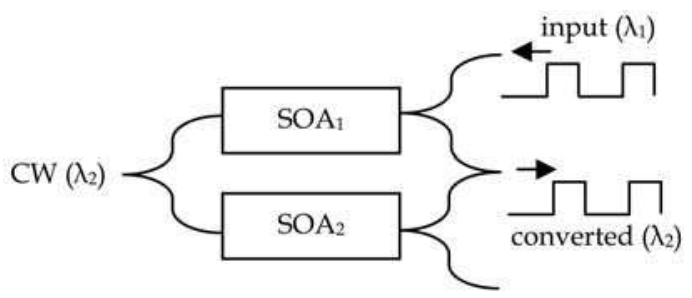

Fig. 8. Cross phase modulation wavelength conversion using SOAs in MZI configuration.
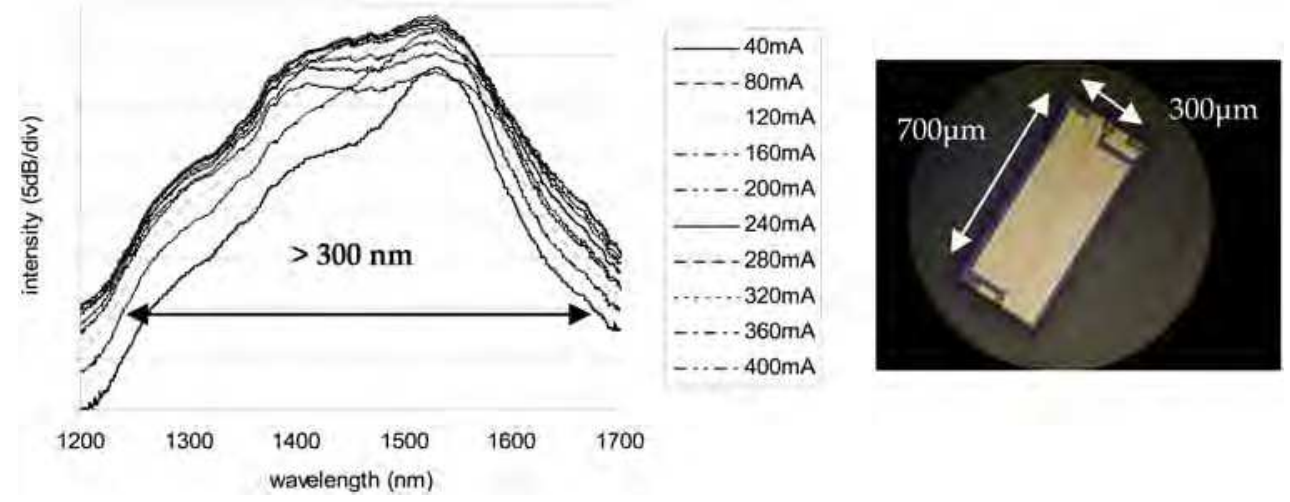

Fig. 9. (a) Spectra of the NWQW-SOA at the bias current from $40 \mathrm{~mA}$ to $400 \mathrm{~mA}$, (b) and its dimensions (Wan et al., 2005).

Wavelength conversion based on a SOA can also be implemented by using cross polarization birefringent switching (XPolS). Fig. 9(a) shows the optical spectra of a nonidentical multiple quantum well (NMQW) SOA, and its photo and dimensions is shown in Fig. 9(b). Due to a more uniform carrier distribution in the quantum well sequence, the NMQW-SOA exhibits an extremely broadband spectrum (1300 nm to $1600 \mathrm{~nm})$. Fig. 10(a) shows the experimental setup of XPolS using the NMQW-SOA. The pump signal ( $\lambda \mathrm{s}$ : $1557.38 \mathrm{~nm})$ and the probe signal $(\lambda \mathrm{p}: 1439.60 \mathrm{~nm})$ were first launched into the SOA. The probe signal was initially coupled into the SOA at $45^{\circ}$ with respect to the transverse-electric (TE) axis of the SOA. The probe was minimized and blocked by the polarizer at the output of the SOA. The pump signal was then injected into the SOA at TE or transverse-magnetic (TM) polarization. The pump depleted the carriers in the SOA and caused refractive index change, which induced a change in birefringence for the probe beam in the SOA and the probe beam was switched "ON" after the polarizer (Wan et al., 2005), as shown in the experimental optical spectra in Fig. 10(b).

Four-wave-mixing (FWM) wavelength conversion can preserve phase information of the input pump signal; and it is an ultrafast process suitable for bit rates beyond $100 \mathrm{~Gb} / \mathrm{s}$ (Kelly et al., 1998). When optical waves mix within the SOA, carrier density pulsation (CDP) occurs due to the beating between the two optical waves which are detuned by less than the frequency response of the carriers (Agrawal, 1988). The conversion efficiency of 
conventional FWM in SOA drops rapidly with wavelength detuning and it is polarization dependent. The drop in conversion efficiency with detuning can be solved by using the broadband orthogonal pump (BOP) FWM (Contestabile et al., 1998, Morgan et al., 1998). One pump beam $\left(\mathrm{P}_{1}\right)$ is polarized parallel to the signal and detuned by a small amount from the signal wavelength (to generate $\mathrm{CDP}$ ), and another pump beam $\left(\mathrm{P}_{2}\right)$ is polarized orthogonal to $\mathrm{P}_{1}$ and interacts with the CDP to produce the desired output wavelength. The problem of polarization dependence in BOP FWM was solved by the polarization diversity loop (Mak et al., 2000). It is possible to eliminate both external laser sources in the BOP FWM by placing the SOA in a double-ring fiber cavity (Chow et al., 2002). High speed wavelength conversion at $160-\mathrm{Gb} / \mathrm{s}$ using FWM in quantum dot (QD) - SOA has been demonstrated (Otsubo et al., 2005).
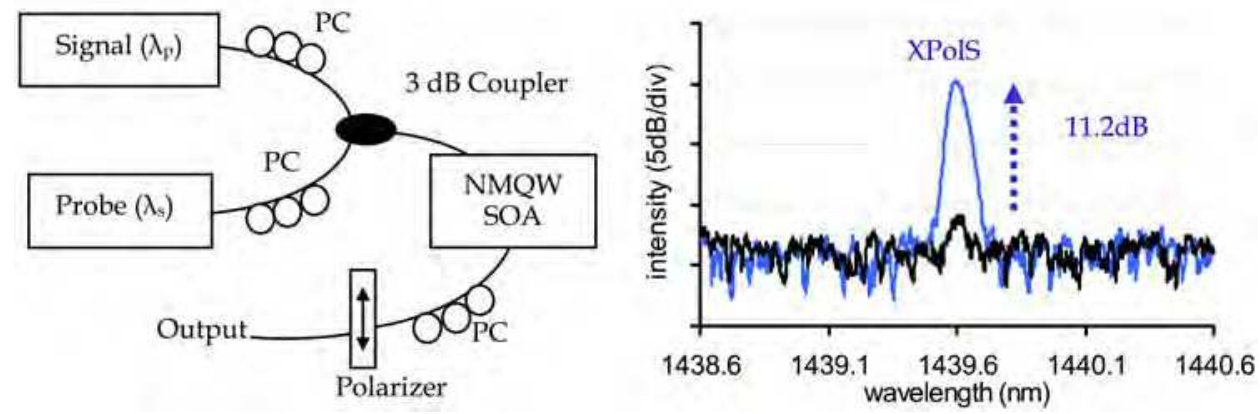

Fig. 10. (a) Experimental setup of XPolS in NMQW-SOA. PC: polarization controller. (b) Optical spectra of the probe signal after the polarizer $(1439.60 \mathrm{~nm})$ with and without the pump signal (1557.38 nm) (Wan et al., 2005).

Fiber based devices are also promising candidates for nonlinear photonic signal processing. High-speed switching is possible because of the non-resonant nature of the fiber nonlinearity. Due to its passive in nature, the fiber length needed to produce the nonlinear effect is usually much longer that that of a semiconductor devices. Commonly used specialty fibers for nonlinear photonic signal processing include dispersion-shifted fiber (DSF), highly nonlinear fiber (HNLF), photonic crystal fiber (PCF) and bismuth oxide fiber. The potential of using specialty fibers for all-optical signal processing have been reviewed (Lee, 2008).

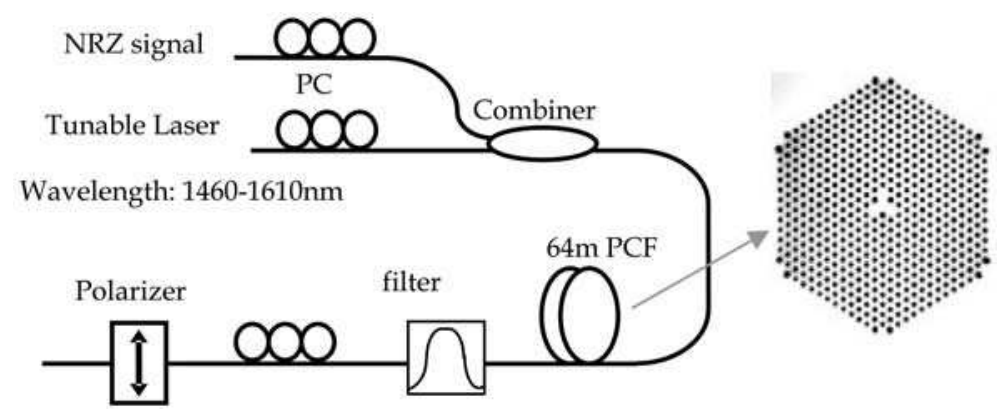

Fig. 11. Experimental setup for the S-, C-, and L-band wavelength conversion us XPolS in a PCF. Inset: cross section of the PCF (Kwok et al., 2006). 

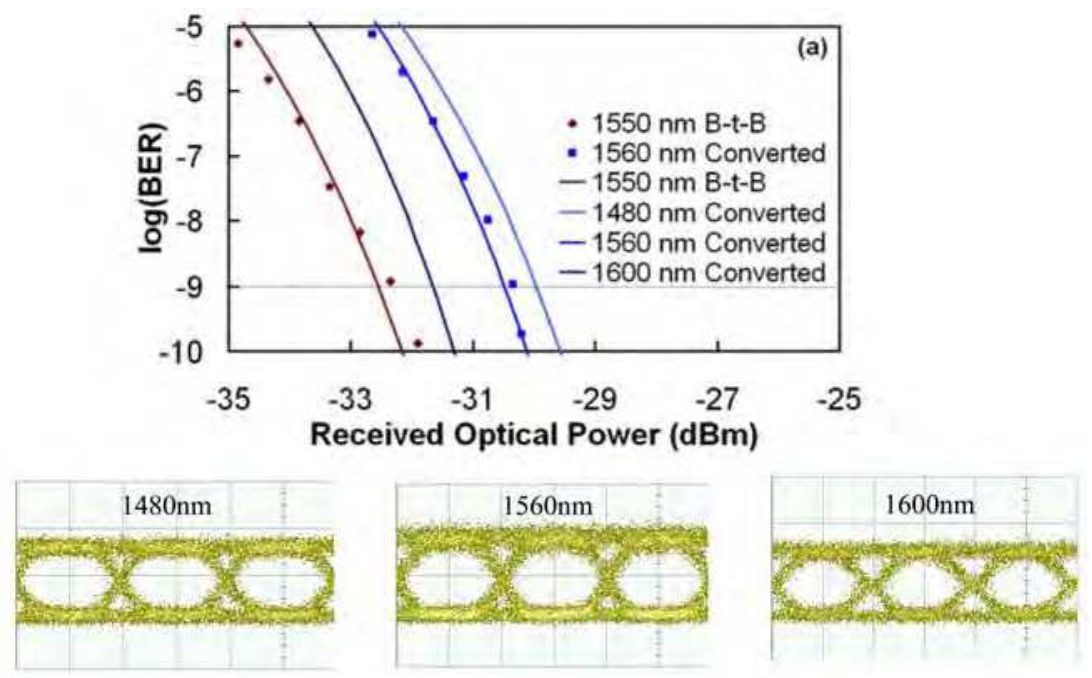

Fig. 12. BER performance of the S-, C-, and L-band wavelength conversion us XPolS in a PCF. Inset: eye diagrams of converted signals at $1480 \mathrm{~nm}, 1560 \mathrm{~nm}$ and $1600 \mathrm{~nm}$ (Kwok et al., 2006).

Here, we describe the XPolS in a dispersion-flattened PCF for ultra-broadband (> $100 \mathrm{~nm}$ ) all-optical wavelength conversion (Kwok et al., 2006). The $64 \mathrm{~m}$ dispersion-flattened PCF (inset of Fig. 11) has a mode field diameter of $3.5 \mathrm{~mm}$ and a non-linear coefficient of 11.2 (W $\mathrm{km})^{-1}$ with dispersion of about $-3 \mathrm{ps} /(\mathrm{km} \mathrm{nm})$ in the range 1500-1600 $\mathrm{nm}$. The dispersion variation is less than $1 \mathrm{ps} /(\mathrm{km} \mathrm{nm})$ in the range of 1465-1655 nm with dispersion slope less than $10^{-3} \mathrm{ps} /\left(\mathrm{km} \mathrm{nm}^{2}\right)$. A CW probe light was launched at an angle of $45^{\circ}$ with respected to the pump signal. At the output of the PCF, a polarizer was used to block the linearly polarized CW probe light in the absence of the pump signal. The linearly polarized pump signal introduced nonlinear phase shifts to the two orthogonal components of the CW probe light with different XPM efficiency. The difference in the overall phase shifts of the two orthogonal components changed the state of polarization of the probe light, and it will turn into a power change at the output of the polarizer. Hence, the intensity modulated pump signal will modulate the intensity of the probe signal after the polarizer. The BER performances of the $1550 \mathrm{~nm}$ back-to-back and the converted signals are shown in Fig. 12 . Figs. 12 also show the experimental eye diagrams of the converted signal at $1480 \mathrm{~nm}, 1560$ $\mathrm{nm}$ and $1600 \mathrm{~nm}$. It was estimated in simulation that the conversion bandwidth for $10 \mathrm{~Gb} / \mathrm{s}$ NRZ signal can be larger than $200 \mathrm{~nm}$ using this approach, while the conversion bandwidth of $90 \mathrm{~nm}$ can also be achieved for $40 \mathrm{~Gb} / \mathrm{s}$ NRZ signals.

\subsection{WDM-to-OTDM and OTDM-to-WDM conversions and demultiplexing}

As mentioned in the introduction, the scalability of the optical technologies and the elimination of expensive $\mathrm{O} / \mathrm{E}$ and $\mathrm{E} / \mathrm{O}$ conversions are expected to significantly reduce the cost and power consumption in future Internet. Initial commercial activities happen, consisting of several regional systems that are interconnected via reconfigurable optical add-drop multiplexers (ROADMs) and optical cross connects (OXCs) to provide 
transparency extending over a substantial portion of a continental area (Sygletos et al., 2008, Fishman et al., 2006). Recently, an European funded project TRIUMPH (Transparent Ring Interconnection Using Multi-wavelength Photonic switches) has been carried out. It proposes the multi-wavelength photonic switches that perform optical processing including transparent optical grooming/aggregation and multi-wavelength optical regeneration. The proposed network node can support high capacity with transparent connectivity between core-rings (> $100 \mathrm{~Gb} / \mathrm{s}$ ) and metro-rings (up to $40 \mathrm{~Gb} / \mathrm{s}$ ). Inside the photonic node (Ellis et al., 2008), traffic from the metro-rings is switched by an OXC to either metro-ring or via the add-path to the core-ring. In the add-path, asynchronous data packets from the metro-ring are launched into the WDM-to-OTDM converter (Ellis et al., 2008, Norte \& Willner, 1996), where each optical packet is re-timed to a local clock and wavelength converted to the desired wavelength. Afterward, the re-timed optical packets are time interleaved (transmultiplexed) to form the OTDM signal for the core-ring. The re-timing can be performed by using an asynchronous digital optical regenerator (ADORE) (Cotter \& Ellis, 1998, Chow et al., 2007, Ibrahim et al., 2008, Ibrahim et al., 2008, Chow et al., 2009). For exiting the core-ring, the OTDM signal is simultaneously extracted to WDM signals using multi-wavelength probe signals applied to an OTDM-to-WDM converter. Each demultiplexed WDM signal then passes to the OXC, where it is transmitted to either of the metro-rings or back to the core-ring via the ADORE modules. A field trial of the WDM-toOTDM trans-multiplexing employing the ADORE has been demonstrated recently (Zarris et al., 2009).
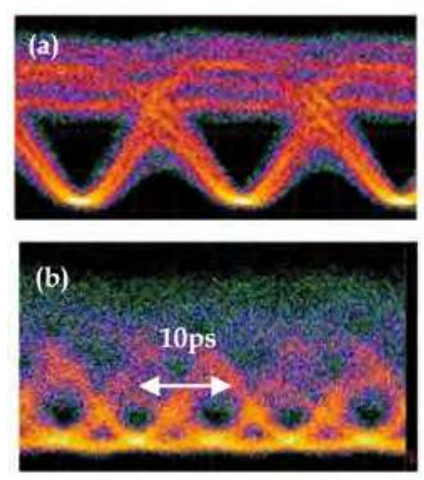

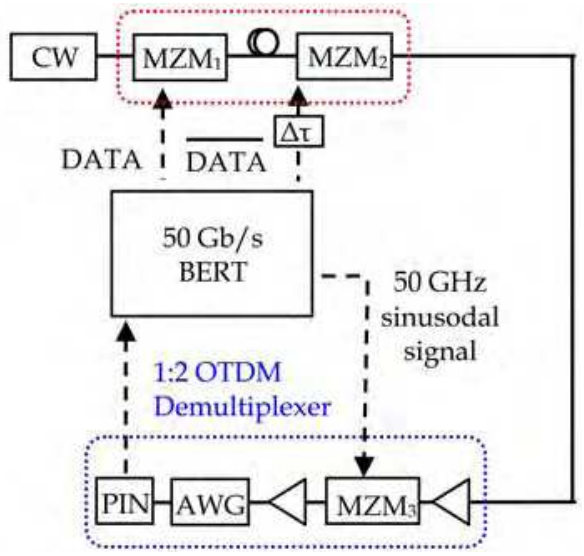

Fig. 13. Experiment setup of $100 \mathrm{~Gb} / \mathrm{s}$ transmitter and demultiplexer. MZM: Mach-Zehnder modulator, AWG: arrayed waveguide grating. (a) Experimental $50 \mathrm{~Gb} / \mathrm{s}$ eyes after $\mathrm{MZM}_{1}$ and (b) $100 \mathrm{~Gb} / \mathrm{s}$ SDRZ eyes after $\mathrm{MZM}_{2}$ (Ellis \& Chow, 2006).

We then describe the generation of a single channel $100 \mathrm{~Gb} / \mathrm{s}$ signal. Several groups have proposed and demonstrated $100 \mathrm{~Gb} / \mathrm{s}$ transmitters, such as using NRZ (Schuh et al., 2007), duo-binary (Winzer et al., 2005), and differential quadrature phase shift keying (DQPSK) (Daikoku et al., 2006) and serial dark-return-to-zero (SDRZ) (Ellis \& Chow, 2006). Fig. 13 shows the SDRZ optical transmitter, which was constructed by using commercially available $40 \mathrm{~Gb} / \mathrm{s}$ components. A CW signal was launched into a single-drive balanced 33 $\mathrm{GHz}$ Mach-Zehnder modulator $\left(\mathrm{MZM}_{1}\right)$. A $50 \mathrm{~Gb} / \mathrm{s}$ NRZ was applied to $\mathrm{MZM}_{1}$. The MZM 
was biased at the transmission minimum and the NRZ drive voltage switched the modulator towards the two adjacent maxima. At a transition in the NRZ signal, a dark optical pulse with opposite phases between adjacent maxima was produced. The NRZ signal was differentially pre-coded. A second $50 \mathrm{~Gb} / \mathrm{s}$ electrical signal was modulated by $\mathrm{MZM}_{2}$ onto the residual $\mathrm{CW}$ background between the optical dark pulses, so generating a $100 \mathrm{~Gb} / \mathrm{s}$ SDRZ signal. At the receiver side, a 1:2 OTDM demultiplexer converted the 100 $\mathrm{Gb} / \mathrm{s}$ signal down to $50 \mathrm{~Gb} / \mathrm{s}$ using $\mathrm{MZM}_{3}$. The demultiplexed signal was filtered by a standard flat-top 100-GHz AWG with an $80 \mathrm{GHz}$ bandwidth, and then coupled into a 45 GHz PIN photodiode for BER measurements.

Fig. 14 shows an OTDM-to-WDM conversion from $129 \mathrm{~Gb} / \mathrm{s}$ OTDM signal to $3 \times 43 \mathrm{~Gb} / \mathrm{s}$ WDM signals (Vorreau et al., 2008) by using a single NOLM switch (Doran \& Wood, 1988). The scheme is using the ultra-fast Kerr based XPM in a NOLM constructed by a specially designed HNLF. The three WDM probe pulses $\left(\lambda_{1}, \lambda_{2}, \lambda_{3}\right)$ were aligned to different time slots of the OTDM data signal $\left(\lambda_{\text {control }}\right)$ and were launched into the NOLM via $\mathrm{FC}_{2}$. If the OTDM data pulse $\left(\lambda_{\text {control }}\right)$ was logic 'one', the control pulse caused nonlinear phase shift generated by XPM to the co-propagating probe signals. When the two counter-propagating probe signals interfered at the $\mathrm{FC}_{2}$ after they had traversed the loop, the probe signal was transmitted at the output of the NOLM and logic 'one' of the probe signal appeared. If the OTDM data pulse $\left(\lambda_{\text {control }}\right)$ was logic 'zero', the two counter-propagating probe signals had identical phase shifts when they traversed the loop and interfered constructively at the coupler with no signal transmitted at the output port of the NOLM ('zero'). By using an optical filter at the output port of the NOLM, each WDM switched signal can then be properly filtered. For multi-wavelength operation of the NOLM, an accurate control of the dispersion and dispersion slope of the fiber is needed to minimize the walk-off between the control and the WDM channels. OTDM-to-WDM conversions based on SPM (Doran \& Wood, 1988, Morais et al., 2008) and FWM (Awaji et al, 2004) have also been reported. Besides, we can consider OTDM-to-WDM conversion is an example of all-optical demultiplexing, which allows ultra-high speed OTDM data to be time-division demultiplexed into lower bit-rate channels, and recently, $1.28 \mathrm{~Tb} / \mathrm{s}$ and $2.56 \mathrm{~Tb} / \mathrm{s}$ all-optical demultiplexing based on NOLM have been demonstrated (Mulvad et al., 2009, Weber et al., 2006).

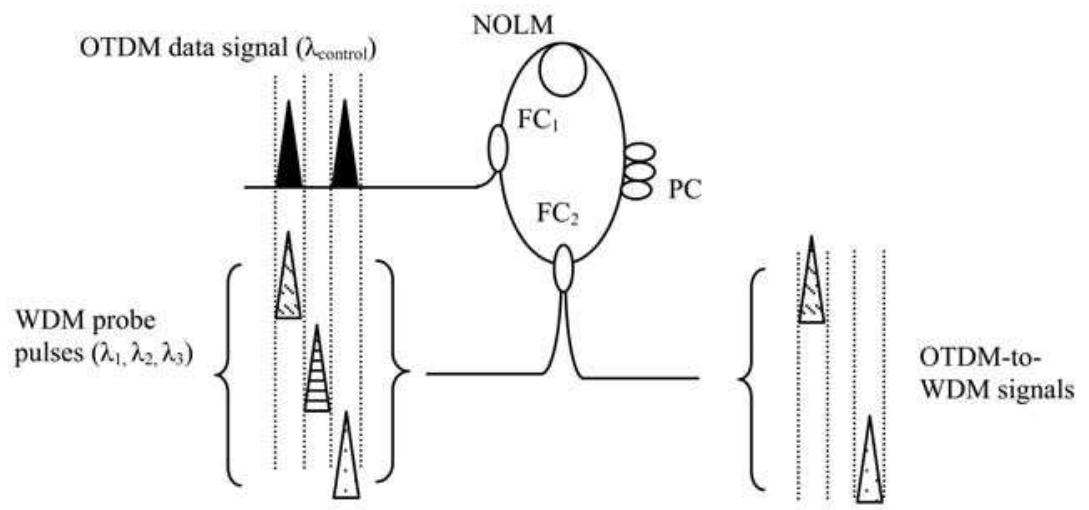

Fig. 14. OTDM-to-WDM conversion using a NOLM. FC: fiber coupler, PC: polarization controller (Vorreau et al., 2008). 


\section{Optical Regeneration}

All-optical regeneration, such as $2 \mathrm{R}$ (re-amplification, re-shaping) and $3 \mathrm{R}$ (re-amplification, re-shaping, re-timing), is another key technology for future Internet to improve the signal quality (Provost et al., 2009). When the data rate is becoming higher and higher (towards 100 $\mathrm{Gb} / \mathrm{s})$, optoelectronic regeneration schemes will be very hard to implement or even impossible. Besides, optoelectronic regeneration generally can only support a single channel, hence, all-optical regeneration supporting multi-wavelength operation can be considered as an economical upgrade. Simple $2 \mathrm{R}$ optical regeneration can be implemented by using an optical nonlinear fiber with an offset optical filter (Mamyshev, 1998), as shown in Fig. 15. Recent studies (Provost et al., 2006, Provost et al., 2007) also allow us to increase the understanding of its operation principle. It was based on self-phase modulation (SPM) that arises when a degraded optical signal is launched into a HLNF, causing the signal spectral broadening. Since the method can produce a steep transfer function, it can reshape the optical pulses by suppressing the amplitude fluctuations in the logic 'one' and 'zero'. An offset optical filter after the HNLF was used to obtain the regenerated output. This scheme can support very high data rates $(>160 \mathrm{~Gb} / \mathrm{s}$ ) and it does not suffer from any carriertransport limitation. This scheme can support single and multi-wavelength channels. However, in the case of multi-wavelength operation, the performance limitation will appear due to the XPM and the FWM produced by the multi-wavelength channels. An improved version of this technique where the XPM can be suppressed is to use an appropriately designed dispersion map by ensuring sufficient walk-off between pulses and minimizing their interaction (Vasilyev \& Lakoba, 2005, Cuenot et al., 2006). Other schemes of multiwavelength all-optical regenerations have also been demonstrated recently using special fibers (Parmigiani et al., 2009, Provost et al., 2008, Provost et al., 2008, Kouloumentas et al., 2008) and QD-SOA (Sygletos et al., 2007, Spyropoulou et al., 2007). 10 Gb/s all-optical signal regeneration over 20,000 km has been demonstrated by Kailight Photonics (Cbayet et al., 2004).

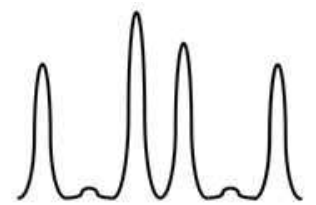

Input signal

Input: logic " $1 "$

Input: logic " 0 "
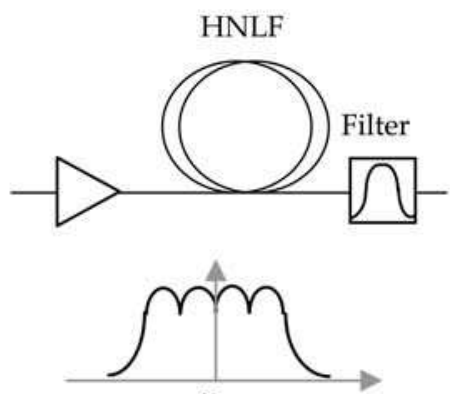

fo

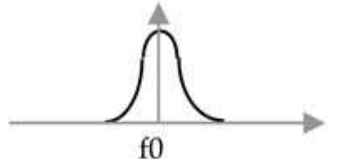

Optical spectra after HNLF

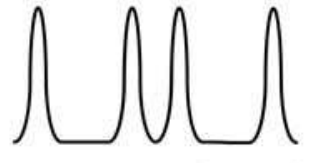

Regenerated signal
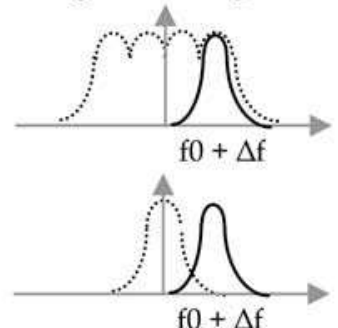

Optical spectra after offset-filter

Fig. 15. 2R all-optical regeneration based on SPM, using a HNLF and an offset filter (Mamyshev, 1998). 


\section{Nonlinear photonic signal processing using SOI}

The potential of low-cost mass production using mature CMOS fabrication facilities makes silicon an attractive platform for the monolithic integration of optical waveguides and alloptical signal processing functional devices. The high index contrast of SOI waveguides (Soref \& Lorenzo, 1985) allows small nano-wire waveguides (core dimensions $\sim 400 \mathrm{~nm}$ ) to be fabricated. Hence the input optical powers at $\mathrm{mW}$ level can produce peak intensities of $\sim 10^{13} \mathrm{~W} \mathrm{~m}^{-2}$. Silicon wire waveguides can have nonlinear parameters $(\mathrm{\gamma})$ of $\sim 10^{6}(\mathrm{~W} \mathrm{~km})^{-1}$ (Koos et al., 2007), which is about 1000 times greater than that of HNLF. Moreover, the Raman gain coefficient in silicon is 1,000 - 10,000 times greater than that in ordinary fiber. All these mean that many of the concepts and applications already developed nowadays that are based on nonlinear effects in semiconductors and fibers can also be adapted for SOI waveguides. Thus, nonlinear optical effects such as SPM (Tsang et al., 2002, Boyraz et al, 2004, Liu et al., 2007), TPA (Liu \& Tsang, 2007, Liang \& Tsang, 2004), stimulated Raman scattering (SRS) (Claps et al., 2002, Claps et al., 2003), XPM (Liang et al., 2005), slow light for tunable optical delay (Okawachi et al., 2006) and optical bistability (Priem et al., 2005) have all been demonstrated.

Although silicon has a higher Raman gain coefficient when compared with silica fiber, the optical loss in silicon is much higher than that in fiber, particularly at high input power. Nonlinear losses due to TPA-induced free-carrier absorption (FCA) (Claps et al., 2004, Rong et al., 2004) become dominant at high input power. Net gain was first achieved in SOI waveguides using pulsed pumping (Liang \& Tsang, 2004). By using a reverse biased p-i-n structure or ion implantation (Liu \& Tsang, 2006), the nonlinear absorption can be significantly reduced and CW net Raman gain can be realized (Jones et al., 2005, Sih et al., 2007). After the realization of optical Raman amplification, silicon Raman lasers can be constructed by forming a laser cavity using hybrid fiber loop (Boyraz \& Jalali, 2004), chip facet coatings (Rong et al, 2005) or a fully monolithic integrated ring cavity (Rong et al., 2006). Besides, hybrid silicon evanescent laser utilizes a silicon waveguide bonded to AlGaInAs quantum wells is demonstrated (Park et al., 2005). All-optical wavelength conversion can be implemented in SOI using FWM (Raghunathan et al., 2004, Rong et al., 2006), and recently error-free $40 \mathrm{~Gb} / \mathrm{s}$ wavelength conversion using SOI has been implemented (Kuo et al., 2006). In 2009, $107.8 \mathrm{~Gb} / \mathrm{s}$ all-optical demultiplexing using FWM in the silicon-organic hybrid (SOH) waveguides has been demonstrated (Koos et al., 2009). This paves the way to the realization of integrated silicon photonic chip for future ultra-fast photonic signal processing.

\section{Conclusion}

Nonlinear photonic signal processing towards terabit per second is steadily growing in maturity. In the previous sections, we have briefly described various applications of nonlinear photonic signal processing based on semiconductors, fibers and SOI. Various other nonlinear materials can also be employed for these functionalities, including chalcogenide waveguides, periodicallypoled lithium niobate (PPLN) etc. Although many nonlinear photonic devices have been evaluated in transmission experiments and their usefulness has been demonstrated, there are still many challenges for realizing commercial ultrafast communication networks. However, these challenges so far have given researchers and engineers precious knowledge for the present fruitful and diversify applications of 
ultra-fast photonic signal processing. As the data rate of optical communication will be $>1$ $\mathrm{Tb} / \mathrm{s}$ in the near future, nonlinear photonic signal processing techniques are irreplaceable technologies for the future high speed Internet.

\section{Acknowledgement}

The authors would like to thank Prof. Hon Tsang, Prof. Chinlon Lin, Dr. Andrew Ellis, Prof. Paul Townsend, Dr. Chien-Hung Yeh and Prof. Sien Chi for supports and discussions.

\section{References}

Adler, R. (1946). A study of locking phenomena in oscillators. Proc. IRE, Vol. 34, (1946) pp. 351-357

Agrawal, G. P. (1988). Population pulsations and nondegenerate four-wave mixing in semiconductor lasers and amplifiers. J. of Optic. Soc. of Am. B, Vol. 5, No. 1, (1988) pp.147-158

Awaji, Y.; Miyazaki, T. \& Kubota, F. (2004). 160/4 x 40Gb/s OTDM/WDM conversion using FWM fibre. European Conference on Optical Communication (ECOC), Paper We1.5.6, Sept. 2004, Stockholm, Sweden

Berthelon, L.; Audouin, O.; Bonno, P.; Drion, C.; Grard, E.; Rofidal, O.; Martin, C. M.; Ringoot, E.; Van de Voorde, I.; Eilenberger, G. J.; Raeymaekers, F.; Chauvin, J.; Hoa, D. H. B.; Morin, M.; Qiu, X. Z.; Vandewege, J.; Daeleman, T.; Angelopoulos, J. \& Taille, C. (2000). Design of a cross-border optical core and access networking field trial: First outcomes of the ACTS-PELICAN project. J. Lightwave Technol., Vol.18, No.12, (2000) pp.1939-1954

Birman, A. and Kershenbaum, A. (1995). Routing and wavelength assignment methods in single-hop all-optical networks with blocking. Proceedings of the Fourteenth Annual Joint Conference of the IEEE Computer and Communication Societies, pp. 431, ISBN:08186-6990- X, 1995, IEEE Computer Society Washington, DC, USA

Boyraz, O. \& Jalali, B. (2004). Demonstration of a silicon Raman laser. Opt. Express, Vol. 12, (2004) pp. 5269

Boyraz, O.; Indukuri, T. \& Jalali, B. (2004). Self-phase-modulation induced spectral broadening in silicon waveguides. Opt. Express, Vol. 12, (2004) pp. 829-834

Buczek, C. J. and Frejberg, R. J. (1972). Hybrid injection locking of higher power CO2 lasers. IEEE J. Quantum Electron., Vol. QE-8, (1972) pp. 641-650

Cartledge, J. C. (1990). Theoretical performance of multigigabit-per-second lightwave systems using injection locked semiconductor lasers. J. Lightwave Technol., Vol. 8, (1990) pp. 1017-1022

Caspar, C.; Foisel, H. M.; Patzak, E.; Strebel, B. \& Weich, K. (1996). Improvement of crosstalk tolerance in optical cross-connects by regenerative frequency converters. Electron. Lett., Vol. 32, (1996) pp. 1801-1802

Cbayet, H.; Ben Ema, S.; Sbacbar, N.; Tradok, S.; Tsadka, S. \& Leuthold, J. (2004). Regenerative all-optical wavelength converter based on semiconductor optical amplifier and sharp frequency response filter. Optical Fiber Communication Conference and Exposition (OFC), ThS2, Feb. 2004, Anaheim, USA 
Chan, L. Y.; Chung, W. H.; Wai, P. K. A.; Moses, B.; Tam, H. Y. \& Demokan, M. S. (2002). Simultaneous repolarization of two $10-\mathrm{Gb} / \mathrm{s}$ polarization-scrambled wavelength channels using a mutual-injection-locked laser diode. IEEE Photon. Technol. Lett., Vol. 14, (2002) pp. 1740-1742

Chan, L. Y.; Chung, W. H.; Wai, P. K. A.; Tam, H. Y. \& Demokan, M. S. (2002). All-optical stabilization of state of polarization of high speed pulse train using injection-locked laser diode. Electron. Lett., Vol. 38, (2002) pp. 1116-1118

Chan, L. Y.; Wai, P. K. A.; Lui, L. F. K.; Moses, B.; Chung, W. H.; Tam, H. Y. \& Demokan, M. S. (2003). Demonstration of an all-optical switch by use of multiwavelength mutual injection-locked laser diode. Opt. Lett., Vol. 28, (2003) pp. 837-839

Chang, Y. C.; Lin, Y. H.; Chen, J. \& Lin, G. R. (2004). All-optical NRZ-to-PRZ format transformer with an injection-locked Fabry-Perot laser diode at un-lasing condition. Opt. Express, Vol. 12, (2004) pp.4449-4456

Chen, H. F.; Liu, J. M. \& Simpson, T. B. (2000). Response characteristics of direct current modulation on a bandwidth-enhanced semiconductor laser under strong injection locking. Opt. Commun., Vol. 173, (2000) pp. 349-355

Chow, C. W.; Ellis, A. D. \& Cotter, D. (2007). Asynchronous digital optical regenerator for 4 x $40 \mathrm{Gbit} / \mathrm{s}$ WDM to $160 \mathrm{Gbit} / \mathrm{s}$ OTDM conversion. Opt. Express, Vol. 15, (2007) pp. $8507-8512$

Chow, C. W.; Ellis, A. D. \& Parmigiani, F. (2009). Trans-multiplexer using pulse position locking for $100 \mathrm{~Gb} / \mathrm{s}$ applications. Opt. Express, Vol. 17, (2009) pp. 6562-6567

Chow, C. W.; Wong, C. S. \& Tsang, H. K. (2002). All-optical NRZ to RZ format and wavelength converter by dual-wavelength injection locking. Opt. Comm., Vol. 209, (2002) pp. 329-334

Chow, C. W.; Wong, C. S. \& Tsang, H. K. (2003). All-optical data-format and wavelength conversion in two-wavelength injection locked slave Fabry-Perot laser diodes. Electron. Lett., Vol. 39, (2003) pp. 997-999

Chow, C. W.; Wong, C. S. \& Tsang, H. K. (2003). All-optical RZ to NRZ data format and wavelength conversion using an injection locked laser. Opt. Comm., Vol. 223, (2003) pp. 309-313

Chow, C. W.; Wong, C. S. \& Tsang, H. K. (2004). All-optical ASK/DPSK label-swapping and buffering using Fabry-Perot laser diodes. J. Select. Top. in Quantum Electron., Vol.10, (2004) pp. 363-370

Chow, C. W.; Wong, C. S. \& Tsang, H. K. (2004). All-optical modulation format conversion and multicasting using injection-locked laser diodes. J. Lightwave Technol., Vol. 22, No. 11, (2004) pp. 2386-2392, Nov., 2004

Chow, K. K.; Shu, C.; Mak, M. W. K. \& Tsang, H. K. (2002). Widely tunable wavelength converter using a double-ring fiber laser with a semiconductor optical amplifier" IEEE Photon. Technol. Lett., Vol. 14, No. 10, (2002) pp. 1445-1447

Chung, W. H.; Chan, L. Y.; Tam, H. Y.; Wai, P. K. A. \& Demokan, M. S. (2002). Output polarization control of fiber DFB laser using injection locking. IEEE Photon. Technol. Lett., Vol. 14, (2002) pp. 920-922

Claps, R.; Dimitropoulos, D.; Han, Y. \& Jalali, B. (2002). Observation of Raman emission in silicon waveguides at $1.54 \mu \mathrm{m}$. Opt. Express, Vol. 10, (2002) pp. 1305-1313 
Claps, R.; Dimitropoulos, D.; Raghunathan, V.; Han, Y. \& Jalali, B. (2003). Observation of stimulated Raman amplification in silicon waveguides. Opt. Express, Vol. 11, pp. 1731- 1739

Claps, R.; Raghunathan, V.; Dimitropoulos, D. \& Jalali, B. (2004). Role of nonlinear absorption on Raman amplification in silicon waveguides. Opt. Express, Vol. 12, (2004) pp. 2774-2780

Contestabile, G.; Martelli, F.; Mecozzi, A.; Graziani, L.; D'Ottavi, A.; Spano, P.; Guekos, G.; Dall'Ara, R. \& Eckner, J. (1998). Efficiency flattening and equalization of frequency upand down-conversion using four-wave mixing in semiconductor optical amplifiers. IEEE Photon. Technol. Lett., Vol. 10, No. 10, (1998) pp.1398-1400

Cotter, D. \& Ellis, A. D. (1998). Asynchronous digital optical regeneration and networks. J. Lightwave Technol., Vol. 16, (1998) pp.2068-2080

Cuenot, B.; Ellis, A. D. \& Richardson, D. J. (2006). Optical regeneration using self phase modulation and Quasi-continuous filtering. IEEE Photon. Technol. Lett., Vol. 18, (2006) pp.1350-1352

Daikoku, M.; Morita, I.; Taga, H.; Tanaka, H.; Kawanishi, T.; Sakamoto, T.; Miyazaki, T.; \& Fujita, T. (2006). 100Gbit/s DQPSK transmission experiment without OTDM for 100G Ethernet Transport. Optical Fiber Communication Conference and Exposition (OFC), PDP36, March 2006, Anaheim, USA

Doran, N. J. \& Wood, D. (1988). Nonlinear-optical loop mirror. Optics Lett., Vol.13, No. 1, (1988) pp. 56-58

Durhuus, T.; Joergensen, C.; Mikkelsen, B.; Pedersen, R. J. S. \& Stubkjaer, K. E. (1994). Alloptical wavelength conversion by SOA's in a Mach-Zehnder configuration. IEEE Photon. Technol. Lett., Vol. 6, (1994) pp. 53-55

Durhuus, T.; Mikkelsen, B.; Joergensen, C.; Danielsen, S. L. \& Stubkjaer, K. (1996). All-optical wavelength conversion by semiconductor optical amplifiers. J. of Lightwave Technol., Vol. 14, (1996) pp. 942-954

Eiselt, M.; Pieper, W. \& Weber, H. G. (1995). SLALOM: semiconductor laser amplifier in a loop mirror. J. Lightwave Technol. Lett., Vol. 13, (1995) pp. 2099-2112

Ellis, A. D. \& Chow, C. W. (2006). Serial OTDM for 100 GB-ethernet applications. Electron. Lett., Vol. 42, (2006) pp. 485-486

Ellis, A. D.; Cotter, D.; Ibrahim, S.; Weerasuriya, R.; Chow, C. W.; Leuthold, J.; Freude, W.; Sygletos, S.; Vorreau, P.; Bonk, R.; Hillerkuss, D.; Tomkos, I.; Tzanakaki, A.; Kouloumentas, C.; Richardson, D. J.; Petropoulos, P.; Parmigiani, F.; Zarris, G. \& Simeonidou, D. (2008). Optical interconnection of core and metro networks [Invited]. J. Optical Networking, Vol. 7, (2008) pp. 928-934

Ellis, A. D.; Kelly, A. E.; Nesset, D.; Pitcher, D.; Moodie, D. G. \& Kashyap, R. (1998). Error free 100Gbit/s wavelength conversion using grating assisted cross-gain modulation in 2mm long semiconductor amplifier. Electron. Lett., Vol. 34, (1998) pp. 1958-1559 EU project Triumph, http://www.ihq.unikarlsruhe.de/research/projects/TRIUMPH/

Fishman, D.; Correa, D. L.; Goode, E. H.; Downs, T. L.; Ho, A. Y.; Hale, A.; Hofmann, P.; Basch, B. \& Gringeri, S. (2006). The rollout of optical networking: LambdaXtreme national network deployment. Bell Lab. Tech. J., Vol. 11, (2006) pp.55-63 
Froberg, M. N.; Henion, S. R.; Rao, H. G.; Hazzard, B. K.; Parikh, S.; Romkey, B. R. \& Kuznetsov, M. (2000). The NGI ONRAMP test bed: reconfigurable WDM technology for next generation regional access networks. J. Lightwave Technol., Vol.18, No.12, (2000) pp.1697-1708

Girardin, F.; Guekos, G. \& Houbavlis, H. (1998). Gain recovery in bulk semiconductor optical amplifiers. IEEE Photonics Technol. Lett., Vol. 10, (1998) pp. 784-786

Gomatam, B. N. and DeFonzo, A. P. (1990). Theory of hot carrier effects on nonlinear gain in GaAs-GaAlAs lasers and amplifiers. IEEE J. Quantum Electron., Vol. 26, (1990) pp. 1689- 1703

Horer, J. and Patzak, E. (1997). Large-signal analysis of all-optical wavelength conversion using two-mode injection-locking in semiconductor. IEEE J. Quantum Electron., Vol. 33, (1997) pp. 596-608

Ibrahim, S. K.; Hillerkuss, D.; Weerasuriya, R.; Zarris, G.; Simeonidou, D.; Leuthold, J. \& Ellis, A. D. (2008). Novel $42.65 \mathrm{Gbit} / \mathrm{s}$ dual gate asynchronous digital optical regenerator using a single MZM. European Conference on Optical Communication (ECOC), paper Tu4.D.3., Brussels, Belgium, Sept. 21-25, 2008

Ibrahim, S. K.; Weerasuriya, R.; Hillerkuss, D.; Zarris, G.; Simeonidou, D.; Leuthold, J.; Cotter, D. \& Ellis, A. D. (2008). Experimental demonstration of 42.6 Gbit/s asynchronous digital optical regenerators. International Conference on Transparent Optical Networks (ICTON), invited paper We.C3.3., Athens, Greece, Jun. 22- 26, 2008

Idler, W.; Daub, K.; Deppisch, B.; Dutting, K.; Klenk, M.; Lach, E.; Laube, G.; Luz, G.; Schilling, M.; Ulmer, M. \& Wunstel, K. (1996). All optical wavelength converter modules for operation up to $10 \mathrm{Gbit} / \mathrm{s}$. European Conference on Optical Communication (ECOC), ThB. 2.4, Oslo, Norway, September 15-19,1996

Idler, W.; Schilling, M.; Daub, K.; Baums, D.; Korner, U.; Lach, E.; Laube, E. \& Wunstel, K. (1995). Signal quality and BER performance improvement by wavelength conversion with an integrated three-port Mach-Zehnder interferometer. Electron. Lett., Vol. 31, (1995) pp. 454-455

Inoue, K. and Oda, K. (1995). Noise suppression in wavelength conversion using a lightinjected laser diode. IEEE Photon. Technol. Lett., Vol. 7, (1995) pp. 500-502

Iwashita, K. and Nakagawa, K. (1982). Suppression of mode partition noise by laser diode light injection. IEEE J. Quantum Electron., Vol. QE-18, (1982) pp. 1669-1674

Jones, R.; Rong, H.; Liu, A.; Fang, A.; Paniccia, M.; Hak, D.; \& Cohen, O.; (2005). Net continuous wave optical gain in a low loss silicon-on-insulator waveguide by stimulated Raman scattering. Opt. Express, Vol. 13, (2005) pp. 519-525

Kakagawa, J.; Marhic, M. E. \& Kazovskty, L. G. (2001). All-optical 3R regeneration technique using injection-locking in gain-switched DFB-LD. Electron. Lett., Vol. 37, (2001) pp. 231- 232

Kehayas, E. (2009). EUROFOS Workshop on Photonic Systems (WORPS): Technologies for developing terabit capacity switching systems, International Conference on Transparent Optical Networks (ICTON), Azores, June 2009

Kelly, A. E.; Ellis, A. D.; Nesset, D.; Kashyap, R. \& Moodie, D. G. (1998). 100Gbit/s wavelength conversion using FWM in an MQW semiconductor optical amplifier. Electron. Lett., Vol. 34, No. 20, (1998) pp. 1955-1956 
Kobayashi, S.; Yamada, J.; Machida, S. \& Kimura, T. (1980). Single mode operation of 500 Mbit/s modulated AlGaAs semiconductor laser. Electron. Lett., Vol. 16, (1980) pp. 746- 747

Koos, C.; Jacome, L.; Poulton, C.; Leuthold, J. \& Freude, W. (2007). Nonlinear silicononinsulator waveguides for all-optical signal processing. Opt. Express, Vol. 15, (2007) pp. 5976-5990

Koos, C.; Vorreau, P.; Vallaitis, T.; Dumon, P.; Bogaerts, W.; Baets, R.; Esembeson, B.; Biaggio, I.; Michinobu, T.; Diederich, F.; Freude, W. \& Leuthold, J. (2009). Alloptical high-speed signal processing with silicon-organic hybrid slot waveguides. Nat. Photon., Vol. 3, (2009) pp.216 - 219

Kouloumentas, C.; Provost, L.; Parmigiani, F.; Tsolakidis, S.; Petropoulos, P.; Tomkos, I. \& Richardson, D. J. (2008). Four-channel all-fiber dispersion-managed 2R regenerator. IEEE Photon. Technol. Lett., Vol. 20, (2008) pp. 1169-1171

Kuo, Y. H.; Rong, H.; Sih, V.; Xu, S.; Paniccia, M. \& Cohen, O. (2006). Demonstration of wavelength conversion at $40 \mathrm{~Gb} / \mathrm{s}$ data rae in silicon waveguides. Opt. Express, Vol. 14, (2006) pp. 11721,

Kuramoto, A. and Yamashita, S. (2003). All-optical regeneration using a side-mode injectionlocked semiconductor laser. J. Select. Topics in Quantum Electron., Vol. 9, (2003) pp. 1283-1287

Kurokawa, K. (1973). Injection locking of microwave solid-state oscillators. Proc. IEEE, Vol. 61, (1973) pp. 1386-1410

Kwok, C. H.; Chow, C. W.; Tsang, H. K.; Lin, Chinlon \& Bjarklev, A. (2006). Nonlinear polarization rotation in a dispersion-flattened photonic-crystal fiber for ultra-wide band (> $100 \mathrm{~nm}$ ) all-optical wavelength conversion of $10 \mathrm{~Gb} / \mathrm{s}$ NRZ signals. Opt. Lett., Vol. 31, No. 12, (June, 2006) pp. 1782-1784

Lang, R. (1982). Injection locking properties of a semiconductor laser. IEEE J. Quantum Electron., Vol. QE-18, (1982) pp. 976-983

Lang, R. and Kobayashi, K. (1977). Suppression of relaxation oscillation in the modulated output of semiconductor lasers. IEEE J. Quantum Electron., Vol. QE-12, (1977) pp. $520-525$

Lee, J. H. (2008). All-optical signal processing using specialty fibers. Optical Fiber Communication Conference and Exposition (OFC), OTuD7, San Diego, USA, February 24- 28, 2008

Leuthold, J.; Mikkelsen, B.; Raybon, G.; Joyner, C. H.; Pleumeekers, J. L.; Miller, B. I.; Dreyer, K. \& Behringer, R. (2001). All-optical wavelength conversion between 10 and 100 $\mathrm{Gb} / \mathrm{s}$ with SOA delayed-interference configuration. Opt. Quantum Electron., Vol. 33, (2001) pp.939-952

Leuthold, J.; Moller, L.; Jaques, J.; Cabot, S.; Zhang, L.; Bernasconi, P.; Cappuzzo, M.; Gomez, L.; Laskowski, E.; Chen, E.; Wong-Foy, A. \& Griffin, A. (2004). 160 Gb/s SOA alloptical wavelength converter and assessment of its regenerative properties. Electron. Lett., Vol. 40, (2004) pp.554-555

Liang, T. K. \& Tsang, H. K. (2004). Efficient Raman amplification in silicon-on-insulator waveguides. Appl. Phys. Lett., Vol. 85, (2004) pp. 3343-3345. 
Liang, T. K. and Tsang, H. K. (2004). The role of free-carriers from two-photon absorption in Raman amplification in silicon-on-insulator waveguides. Appl. Phys.Lett., Vol. 84, (2004) pp.2745-2747

Liang, T. K.; Nunes, L.; Sakamoto, T.; Sasagawa, K.; Kawanishi, T.; Tsuchiya, M.; Priem, G.; Van Thourhout, D.; Dumon, P.; Baets, R.; \& Tsang, H. K. (2005). Ultrafast all-optical switching by cross-absorption modulation in silicon wire waveguides. Opt. Express, Vol. 13, pp. 7298-7303

Liao, Y. S,; Kuo, H. C.; Chen, Y. J. \& Lin, G. R. (2009). Side-mode transmission diagnosis of a multichannel selectable injection-locked Fabry-Perot Laser Diode with antireflection coated front facet. Opt. Express , Vol. 17, (2009) pp.4859-4867

Lin, C.; Andersen, J. K. \& Mengel, F. (1985). Frequency chirp reduction in a 2.2 Gbit/s directly modulated InGaAsP semiconductor laser by $\mathrm{CW}$ injection. Electron. Lett., Vol. 21, (1985) pp. 80-81

Liu, Y. \& Tsang, H. K. (2006). Nonlinear absorption and Raman gain in helium-ionimplanted silicon waveguides. Opt. Lett., Vol. 31, (2006) pp. 1714-1716

Liu, Y. \& Tsang, H. K. (2007). Time dependent density of free carriers generated by two photon absorption in silicon waveguides. Appl. Phys. Lett., Vol. 90, (2007) 211105

Liu, Y.; Chow, C. W.; Tsang, H. K. \& Wong, S. P. (2007). Enhancement of self phase modulation induced spectral broadening in silicon waveguides by ion implantation. Conference on Lasers and Electro-Optics (CLEO), CThQ2, May 2007, Baltimore, USA

Liu, Y.; Tangdiongga, E.; Li, Z.; de Waardt, H.; Koonen, A. M. J.; Khoe, G. D.; Dorren, H. J. S.; Shu, X. \& Bennion, I. (2006). Error-free $320 \mathrm{~Gb} / \mathrm{s}$ SOA-based wavelength conversion using optical filtering. Optical Fiber Communication Conference and Exposition (OFC), PDP28, March 2006, Anaheim, USA

Liu, Y.; Tangdiongga, E.; Li, Z.; de Waardt, H.; Koonen, A. M. J.; Khoe, G. D.; Shu, X.; Bennion, I. \& Dorren, H. J. S. (2007). Error-free 320-Gb/s all-optical wavelength conversion using a single semiconductor optical amplifier. J. Lightwave Technol., Vol. 25, (2007) pp.103-108

Lu, H. H.; Chuang, Y. W.; Chen, G. L.; Liao, C. W. \& Chi, Y. C. (2006). Fiber optical CATV system performance improvement employing light injection and optoelectronic feedback techniques. IEEE Photon. Technol. Lett., Vol. 18, (2006) pp. 1789-1791

Lu, H. H.; Ho, W. J.; Lin, W. I.; Peng, H. C.; Lai, P, C. \& Yee, H. (2008). Radio-on-DWDM transport systems based on injection-locked Fabry-Perot laser diodes. IEICE Transactions on Communications, Vol. E91-B(3), (2008) pp. 848-853

Lu, H. H.; Tzeng, S. J.; Chuang, C. P.; Chi, Y. C.; Tsai, C. C.; Chen, G. L. \& Chuang, Y. W. (2006). HDTV/ Gigabit ethernet over bidirectional WDM-PON based on injectionlocked Fabry-Perot laser diodes. Opt. Commun., Vol. 267, (2006) pp.102-107

Mak, M. W. K.; Tsang, H. K. \& Chan, K. (2000). Widely tunable polarization-independent all-optical wavelength converter using a semiconductor optical amplifier. IEEE Photon. Technol. Lett., Vol.12, (2000) pp.525-527

Mamyshev, P. V. (1998). All-optical data regeneration based on self-phase modulation effect. European Conference on Optical Communication (ECOC), pp. 475-476, Sept 20-24, 1998, Madrid, Spain 
Manning, R. J.; Davies, D. A. O. \& Lucek, J. K. (1994). Recovery rates in semiconductor laser amplifiers: optical and electrical bias dependencies. Electron. Lett., Vol. 30, (1994) pp. 1233-1234

Manning, R. J.; Yang, X.; Webb, R. P.; Giller, R.; Gunning, F.C. Garcia \& Ellis, A. D. (2006). The 'Turbo-switch' - a novel technique to increase the high-speed response of SOAs for wavelength conversion," Optical Fiber Communication Conference and Exposition (OFC), Paper OWS8, March 5-10, 2006, Anaheim, USA

Mogensen, F.; Olesen, H. \& Jacobsen, G. (1985). FM noise suppression and linewidth reduction in an injection-locked semiconductor laser. Electron. Lett., Vol. 21, (1985) pp. 696-697

Mogensen, F.; Olesen, H. \& Jacobsen, G. (1985). Locking conditions and stability properties for a semiconductor laser with external light injection. IEEE J. Quantum Electron., Vol. QE-21, (1985) pp. 784-793

Morais, R.; Meleiro, R.; Monteiro, P.; \& Marques, P. (2008). OTDM-to-WDM conversion based on wavelength conversion and time gating in a single optical gate. Optical Fiber Communication Conference and Exposition (OFC), OTuD5, February 24-28, 2008, San Diego, USA

Morgan, T. J.; Lacey, J. P. R. \& Tucker, R. S. (1998). Widely tunable four-wave mixing in semiconductor optical amplifiers with constant conversion efficiency. IEEE Photon. Technol. Lett., Vol. 10, No. 10, (1998) pp.1401-1403

Mork, J. and Mark, J. (1994). Carrier heating in InGaAsP laser amplifiers due to two photon absorption. Appl. Phys. Lett., Vol. 64, (Apr. 1994) pp. 2206-2208

Mulvad, H. C.; Oxenløwe, L. K.; Galili, M.; Clausen, A. T.; Grüner-Nielsen, L. \& Jeppesen, P. (2009). $1.28 \mathrm{Tbit} / \mathrm{s}$ single-polarisation serial OOK optical data generation and demultiplexing. Electron. Lett., Vol. 45, (2009) pp. 280-281

Murakami, A.; Kawashima, K. \& Atsuki, K. (2003). Cavity resonance shift and bandwidth enhancement in semiconductor lasers with strong light injection. IEEE J. Quantum Electron., Vol. 39, (2003) pp. 1196-1204

Nakamura, S.; Ueno, Y. \& Tajima, K. (2001). 168-Gb/s all-optical wavelength conversion with a symmetric-Mach-Zehnder-Type switch. IEEE Photon. Technol. Lett., Vol. 13, (2001) pp.1091-1093

Nielsen, M. L. \& Mørk, J. (2004). Increasing the modulation bandwidth of semiconductoroptical- amplifier-based switches by using optical filtering. J. Opt. Soc. Am. B, Vol. 21, (2004) pp.1606-1619

Nielsen, M. L.; Mørk, J.; Suzuki, R.; Sakaguchi, J. \& Ueno, Y. (2006). Experimental and theoretical investigation of the impact of ultra-fast carrier dynamics on high-speed SOA-based all-optical switches. Opt. Express, Vol. 14, (2006) pp.331-347

Norte, D. \& Willner, A. E. (1996). All-optical data format conversions and reconversions between the wavelength and time domains for dynamically reconfigurable WDM networks. J. Lightwave Technol., Vol. 14, (1996) pp. 1170-1182

Okawachi, Y.; Foster, M.; Sharping, J.; Gaeta, A.; Xu, Q.; \& Lipson, M. (2006). All-optical slow-light on a photonic chip. Opt. Express, Vol. 14, pp. 2317-2322

Otsubo, K.; Akiyama, T.; Kuwatsuka, H.; Hatori, N.; Ebe, H. \& Sugawara, M. (2005). Automatically controlled C-band wavelength conversion with constant output 
power based on four-wave mixing in SOA's. IEICE Trans. Electron., Vol. E88-C, (2005) pp. 2358-2365

Park, H.; Fang, A. W.; Kodamaa, S.; \& Bowers, J. E. (2005). Hybrid silicon evanescent laser fabricated with a silicon waveguide and III-V offset quantum wells. Opt. Express, Vol. 13, No. 23, (2005) pp. 9460-9464

Parmigiani, F.; Vorreau, P.; Provost, L.; Mukasa, K.; Takahashi, M.; Tadakuma, M.; Petropoulos, P.; Richardson, D. J.; Freude, W. \& Leuthold, J. (2009). 2R regeneration of two $130 \mathrm{Gbit} / \mathrm{s}$ channels within a single fiber. Optical Fiber Communication Conference and Exposition (OFC), JThA56, March 22.-26, 2009, San Diego, USA

Patel, N. S.; Rauschenbach, K. A. \& Hall, K. L. (1996). 40-Gb/s demultiplexing using an ultrafast nonlinear interferometer (UNI). IEEE Photon. Technol. Lett., Vol. 8, No. 12, (1996) pp. 1695-1697

Piazzolla, S.; Spano, P. \& Tamburrini, M. (1986). Small signal analysis of frequency chirping in injection-locked semiconductor laser. IEEE J. Quantum Electron., Vol. QE-22, (1986) pp. 2219-2223

Priem, G.; Dumon, P.; Gogaerts, W.; Van Thourhout, D.; Morthier, G. \& Beats, R. Optical bistability and pulsating behaviour in silicon-on-insulator ring resonator structures. Opt. Express, Vol. 13, (2005) pp. 9623

Provost, L.; Finot, C.; Mukasa, K.; Petropoulos, P. \& Richardson, D. J. (2007). Generalisation and experimental validation of design rules for self-phase modulation-based 2Rregenerators. Optical Fiber Communication Conference and Exposition (OFC), OThB6, March 25 - 29, 2007, Anaheim, USA

Provost, L.; Finot, C.; Petropoulos, P. \& Richardson, D. J. (2006). Design scaling laws for selfphase modulation-based 2R-regenerators. European Conference on Optical Communication (ECOC), We4.3.2, Sept 2006, Cannes, France

Provost, L.; Parmigiani, F.; Petropoulos, P. \& Richardson, D. J. (2008). Investigation of simultaneous $2 \mathrm{R}$ regeneration of two $40 \mathrm{~Gb} / \mathrm{s}$ channels in a single optical fiber. IEEE Photon. Technol. Lett., Vol. 20, (2008) pp.270-272

Provost, L.; Parmigiani, F.; Petropoulos, P.; Finot, C.; Mukasa, K.; Petropoulos P. \& Richardson, D. J. (2008). Analysis of a two-channel 2R all-optical regenerator based on a counter-propagating configuration. Opt. Express, Vol. 16, (2008) pp. 2264-2275

Provost, L.; Petropoulos, P. \& Richardson, D. J. (2009). Optical WDM regeneration: status and future prospects. Optical Fiber Communication Conference and Exposition (OFC), OFD7, Mar 22-26, 2009, San Diego, USA

Raghavan, P. and Upfal, E. (1994). Efficient routing in all-optical networks. Proceedings of the ACM Symposium on Theory of Computing, pp.134--143, 1994

Raghunathan, V.; Claps, R.; Dimitropoulos, D. \& Jalali, B. (2004). Wavelength conversion in silicon using Raman induced four-wave mixing. Appl. Phys. Lett., Vol. 85, (2004) pp. 34- 36

Ramaswami, R. and Sivarajan, K. N. (1994). Routing and wavelength assignment in alloptical networks. IEEE/ACM Transactions on Networking (TON), Vol.3, No. 5, (October 1995) pp.489-500, ISSN: 1063-6692

Ratovelomanana, F.; Vodjdani, N.; Enard, A.; Glastre, G.; Rondi, D.; Blondeau, R.; Joergensen, C.; Durhuus, T.; Mikkelsen, B.; Stubkjaer, K.E.; Jourdan, A. \& Soulage, G. (1995). An all-optical wavelength-converter with semiconductor optical 
amplifiers monolithically integrated in an asymmetric passive Mach-Zehnder interferometer. IEEE Photon. Technol. Lett., Vol. 7, (1995) pp. 992-994

Rong, H.; Jones, R.; Liu, A.; Cohen, O.; Hak, D.; Fang, A.; \& Paniccia, M.; (2005). A continuous-wave Raman silicon laser. Nature, Vol. 433, (2005) pp. 725-728

Rong, H.; Kuo, Y. H.; Liu, A.; Paniccia, M. \& Cohen, O. (2006). High efficiency wavelength conversion of $10 \mathrm{~Gb} / \mathrm{s}$ data in silicon waveguides. Opt. Express, Vol. 14, (2006) pp. 1182

Rong, H.; Kuo, Y. H.; Xu, S.; Liu, A.; Jones, R.; Paniccia, M.; Cohen, O. \& Raday, O. (2006). Monolithic integrated Raman silicon laser. Opt. Express, Vol. 14, (2006) pp. 6705

Rong, H.; Liu, A.; Nicolaescu, R.; \& Paniccia, M. (2004). Raman gain and nonlinear optical absorption measurement in a low loss silicon waveguide. Appl. Phys. Lett., Vol. 85, (2004) pp. 2196-2198

Schuh, K.; Junginger, B.; Lach, E.; Veith, G.; Lutz, J. \& Möller, M. (2007). Serial 107Gbit/s ETDM NRZ transmission over 320km SSMF. Optical Fiber Communication Conference and Exposition (OFC), OWE2, Mar 25 - 29, 2007, Anaheim, USA

Sih, V.; Xu, S.; Kuo, Y. H.; Rong, H.; Paniccia, M.; Cohen, O. \& Raday, O. (2007). Raman amplification of $40 \mathrm{~Gb} / \mathrm{s}$ data in low-loss silicon waveguides. Opt. Express, Vol. 15, (2007) pp.357

Simpson, T. B. and Liu, J. M. (1995). Bandwidth enhancement and broadband noise reduction in injection-locked semiconductor lasers. IEEE Photon. Technol. Lett., Vol. 7, (1995) pp. 709-711

Simpson, T. B. and Liu, J. M. (1996). Small-signal analysis of modulation characteristics in a semiconductor laser subject to strong optical injection. IEEE Photon. Technol. Lett., Vol. 32, (1996) pp. 1456-1468

Simpson, T. B. and Liu, J. M. (1997). Enhanced modulation bandwidth in injection-locked semiconductor lasers. IEEE Photon. Technol. Lett., Vol. 9, (1997) pp. 1322-1324

Sokoloff, J. P.; Prucnal, P. R.; Glesk, I. \& Kane, M. (1993). A terahertz optical asymmetric demultiplexer (TOAD). IEEE Photon. Technol. Lett., Vol. 5, (1993) pp. 787-790

Soref, R. A. \& Lorenz, J. P. (1985). Single-crystal silicon-a new material for 1.3 and $1.6 \mu \mathrm{m}$ integrated-optical components. Electron. Lett. Vol. 21, (1985) pp. 953-954

Spyropoulou, M.; Sygletos, S. \& Tomkos, I. (2007). Investigation of multi-wavelength regeneration employing quantum dot semiconductor optical amplifiers beyond 40 Gb/s. Intern. Conf. on Transparent Optical Networks (ICTON), Tu.A1.7, July 1-5, 2007, Rome, Italy

Stix, M. S.; Keslar, M. P. \& Ippen, E. P. (1986). Observations of subpicosecond dynamics in GaAlAs laser diodes. Appl. Phys. Lett., Vol. 48, (June 1986) pp. 1722-1724

Stover, H. L. and Steier, W. H. (1966). Locking of laser oscillators by light injection. Appl. Phys Lett., Vol. 8, (1966) pp. 91-93

Sygletos, S.; Spyropoulou, M.; Vorreau, P.; Bonk, R.; Tomkos, I.; Freude; W. \& Leuthold, J. (2007). Multi-wavelength regenerative amplification based on quantum-dot semiconductor optical amplifiers (invited)," Intern. Conf. on Transparent Optical Networks (ICTON), We.D2.5, July 1-5, 2007, Rome, Italy

Sygletos, S.; Tomkos, I. \& Leuthold, J. (2008). Technological challenges on the road toward transparent networking. J. Optical Networking, Vol. 7, (2008) pp.321-350 
Tangdiongga, E.; Liu, Y.; deWaardt, H.; Khoe, G. D. \& Dorren, H. J. S. (2006). 320-to-40-Gb/s demultiplexing using a single SOA assisted by an optical filter. IEEE Photon. Technol. Lett., Vol. 18, (2006) pp.908-910

Tsang, H. K.; Wong, C. S.; Liang, T. K.; Day, I. E.; Roberts, S. W.; Harpin, A.; Drake, J. \& Asghari, M. (2002). Optical dispersion, two-photon absorption and self-phase modulation in silicon waveguides at $1.5 \mu \mathrm{m}$ wavelength. Appl. Phys. Lett., Vol. 80, (2002) pp. 416-419

Ueno, Y.; Nakamura, S. \& Tajima, K. (2002). Nonlinear phase shifts induced by semiconductor optical amplifiers with control pulses at repetition frequencies in the 40-160-GHz range for use in ultrahigh-speed all-optical signal processing. J. Opt. Soc. Am. B, Vol. 19, (2002) pp. 2573-2589

Ueno, Y.; Nakamura, S.; Tajima, K. \& Kitamura, S. (1998). 3.8-THz wavelength conversion of picosecond pulses using a semiconductor delayed-interference signal-wavelength converter (DISC). IEEE Photon. Technol. Lett., Vol. 10, (1998) pp.346-348

Van der Pol, B. (1927). Forced oscillations in a circuit with non-linear resistance. Philosophical Mag., Vol. iii, (1927) pp. 65-80

Vasilyev, M. \& Lakoba, T. (2005). Fibre-based all-optical 2R regeneration for multiple WDM channels. Optical Fiber Communication Conference and Exposition (OFC), OME62, March, 2005, Anaheim, USA

Vorreau, P.; Parmigiani, F.; Mukasa, K.; Ibsen, M.; Petropoulos, P.; Richardson, D. J.; Ellis, A. D.; Freude, W. \& Leuthold, J. (2008). TDM-to-WDM conversion from 130 Gbit/s to $3 \& 43 \mathrm{Gbit} / \mathrm{s}$ using XPM in a NOLM switch. International Conference on Transparent Optical Networks (ICTON), Jun 22- 26, 2008, Athens, Greece

Wan, S. M.; Chow, C. W.; Tsang, H. K.; Su, Y. S. \& Lin, C. F. (2005). Broadband wavelength conversion in semiconductor optical amplifier with non-identical multiple quantum wells. Conference on Lasers and Electro-Optics Pacific Rim (CLEO-PR), CThC3-P18, 2005, Tokyo, Japan

Wang, C. H.; Shih, F. Y.; Yeh, C. H.; Chow, C. W. \& Chi, S. (2009). 10 Gb/s TDM passive optical networks using four wavelengths multiplexed channels. Opt. Commun., Vol. 282, (2009) pp. 2476-2479

Weber, H. G.; Ferber, S.; Kroh, M.; Schmidt-Langhorst, C.; Ludwig, R.; Marembert, V.; Boerner, C.; Futami, F.; Watanabe, S. \& Schubert, C. (2006). Single channel 1.28 Tbit/s and 2.56 Tbit/s DQPSK transmission. Electron. Lett., Vol. 42, (2006) pp. 178179

Weich, K.; Eggemann, R.; Horer, J.; As, D. J.; Mohrle, M. \& Patzak, E. (1994). 10 Gbit/s alloptical clocked decision circuit using two-section semiconductor lasers. Electron. Lett., Vol. 30, (1994) pp. 784-785

Willatzen, M.; Uskov, A.; Mork, J.; Olesen, H.; Tromborg, B. \& Jauho, A. P. (1991). Nonlinear gain suppression in semiconductor lasers due to carrier heating. IEEE Photonics Technol. Lett., Vol. 3, (July 1991) pp. 606-609

Willner, A. E. (2008). All-optical signal processing in next-generation communication systems, Optical Fiber Communication Conference and Exposition (OFC), February 2008, San Diego, USA 
Winzer, P. J.; Raybon, G. \& Duelk, M. (2005). 107-Gb/s optical ETDM transmitter for 100G Ethernet transport. European Conference on Optical Communication (ECOC), Paper Th4.1.1, 2005, Glasgow, USA

Yamashita, S. and Suzuki, J. (2004). All-optical 2R regeneration using a two-mode injectionlocked Fabry-Perot laser diode. IEEE Photon. Technol. Lett., Vol. 16, (2004) pp. $1176-1178$

Yeh, C. H.; Chow, C. W.; Wang, C. H.; Shih, F. Y.; Wu Y. F. \& Chi, S. (2009). Using multimode Fabry-Perot laser without external-injection for wavelength conversion. Electron. Lett., Vol. 45, (2009) pp. 327-329

Yoo, S. J. B. (1996). Wavelength conversion technologies for WDM network applications. J. Lightwave Technol., Vol. 14, (Jun. 1996) pp. 955-966

Zarris, G.; Parmigiani, F.; Hugues-Salas, E.; Weerasuriya, R.; Hillerkuss, D.; Gonzalez, N.A.; Spyropoulou, M.; Vorreau, P.; Morais, R.; Ibrahim, S.K.; Klonidis, D.; Petropoulos, P.; Ellis, A.D.; Monteiro, P.; Tzanakaki, A.; Richardson, D.; Tomkos, I.; Bonk, R.; Freude, W.; Leuthold, J. \& Simeonidou, D. (2009). Field trial of WDM-OTDM transmultiplexing employing photonic switch fabric-based buffer-less bitinterleaved data grooming and all-optical regeneration. Optical Fiber Communication Conference and Exposition (OFC), PDPC10, Mar 22-26, 2009, San Diego, USA 


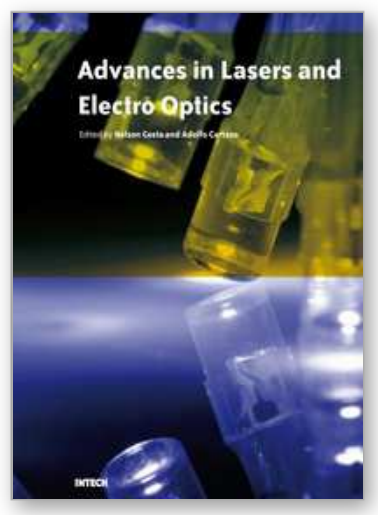

\author{
Advances in Lasers and Electro Optics \\ Edited by Nelson Costa and Adolfo Cartaxo
}

ISBN 978-953-307-088-9

Hard cover, 838 pages

Publisher InTech

Published online 01, April, 2010

Published in print edition April, 2010

Lasers and electro-optics is a field of research leading to constant breakthroughs. Indeed, tremendous advances have occurred in optical components and systems since the invention of laser in the late $50 \mathrm{~s}$, with applications in almost every imaginable field of science including control, astronomy, medicine, communications, measurements, etc. If we focus on lasers, for example, we find applications in quite different areas. We find lasers, for instance, in industry, emitting power level of several tens of kilowatts for welding and cutting; in medical applications, emitting power levels from few milliwatt to tens of Watt for various types of surgeries; and in optical fibre telecommunication systems, emitting power levels of the order of one milliwatt. This book is divided in four sections. The book presents several physical effects and properties of materials used in lasers and electro-optics in the first chapter and, in the three remaining chapters, applications of lasers and electro-optics in three different areas are presented.

\title{
How to reference
}

In order to correctly reference this scholarly work, feel free to copy and paste the following:

Chi-Wai Chow and Yang Liu (2010). Nonlinear Photonic Signal Processing Subsystems and Applications, Advances in Lasers and Electro Optics, Nelson Costa and Adolfo Cartaxo (Ed.), ISBN: 978-953-307-088-9, InTech, Available from: http://www.intechopen.com/books/advances-in-lasers-and-electro-optics/nonlinearphotonic-signal-processing-subsystems-and-applications

\section{INTECH}

open science | open minds

\section{InTech Europe}

University Campus STeP Ri

Slavka Krautzeka 83/A

51000 Rijeka, Croatia

Phone: +385 (51) 770447

Fax: +385 (51) 686166

www.intechopen.com

\section{InTech China}

Unit 405, Office Block, Hotel Equatorial Shanghai

No.65, Yan An Road (West), Shanghai, 200040, China

中国上海市延安西路65号上海国际贵都大饭店办公楼 405 单元

Phone: +86-21-62489820

Fax: $+86-21-62489821$ 
(C) 2010 The Author(s). Licensee IntechOpen. This chapter is distributed under the terms of the Creative Commons Attribution-NonCommercialShareAlike-3.0 License, which permits use, distribution and reproduction for non-commercial purposes, provided the original is properly cited and derivative works building on this content are distributed under the same license. 